\begin{tabular}{|l|l|}
\hline 2. To: (Receiving Organization) & $\begin{array}{l}\text { 3. From: (Originating Organization) } \\
\text { Distribution }\end{array}$ \\
\hline Project W-211 \\
W-211 & $\begin{array}{l}\text { 6. Design Authority/ Design Agent/Cog. } \\
\text { Engr.: } \\
\text { C.A. Rieck }\end{array}$ \\
\hline
\end{tabular}

8. Originator Remarks:

This transmittal is for release of the AP-102/104 Retrieval Control System Qualification test Procedure.

11. Receiver Remarks: 11A. Design Baseline Document? [] Yes [X] No

\begin{tabular}{|c|} 
4. Related EDT No.: \\
N/A \\
$\begin{array}{c}\text { 7. Purchase Order No.: } \\
\text { N/A }\end{array}$ \\
$\begin{array}{c}\text { 9. Equip./Component No.: } \\
\text { N/A }\end{array}$ \\
\hline $\begin{array}{c}\text { 10. System/Bldg./Facility: } \\
\text { Tank Farms }\end{array}$ \\
12. Major Assm. Dwg. No.: \\
N/A \\
\hline 13. Permit/Permit Application No.: \\
N/A \\
\hline 14. Required Response Date: \\
N/A
\end{tabular}

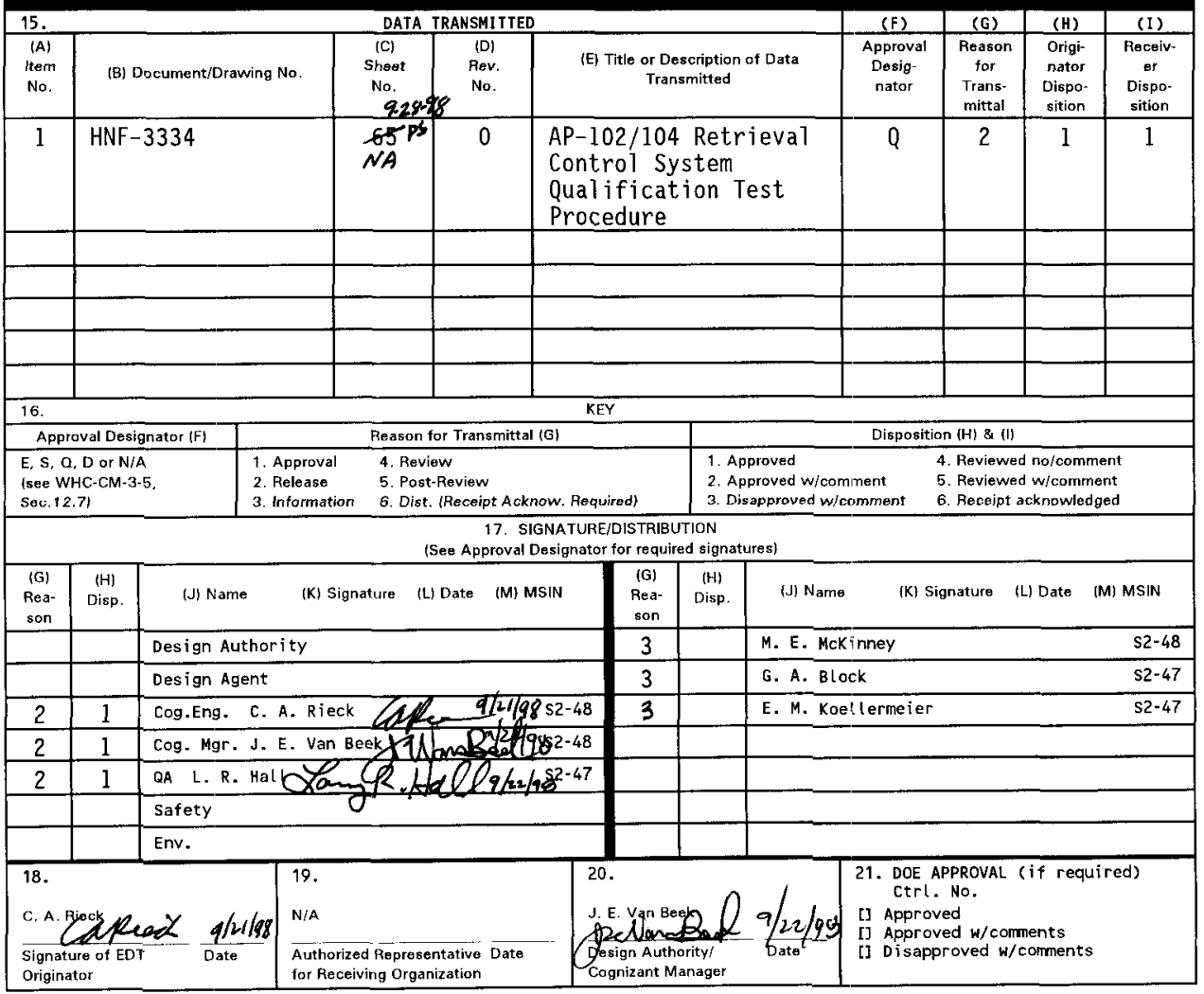

BD-7400-172-2 (05/96) GEF097 


\title{
AP-102/104 Retrieval control System Qualification Test Procedure
}

\author{
C. A. Rieck \\ Numatec Hanford Corporation, Richland, WA 99352 \\ U.S. Department of Energy Contract DE-AC06-96RL13200 \\ EDT/ECN: 625059 \\ UC: 2030 \\ Org Code: $8 \mathrm{C} 620$ \\ Charge Code: 03220 \\ B\&R Code: $39 E W 31301$ \\ Tota1 Pages: 65
}

Key Words: Retrieval Control System, Qualification Test, Project W-211, Initial Tank Retrieval Systems

Abstract: This Qualification Test Procedure documents the results of the qualification testing that was performed on the Project W-21l, "Initial Tank Retrieval Systems," retrieval control system (RCS) for tanks 241-AP-102 and 241-AP-104. The results confirm that the RCS has been programmed correctly and that the two related hardware enclosures have been assembled in accordance with the design documents.

TRADEMARK DISCLAIMER. Reference herein to any specific comercial product, process, or service by trade name, trademark, manufacturer, or otherwise, does not necessarily constitute or imply its endorsement, recommendation, or favoring by the United States Government or any agency thereof or its contractors or subcontractors.

Printed in the United States of America. To obtain copies of this document, contact: Document Control Services, P.0. BOx 950, Mailstop H6-08, Richland WA 99352, Phone (509) 372-2420;

Fax (509) 376-4989.
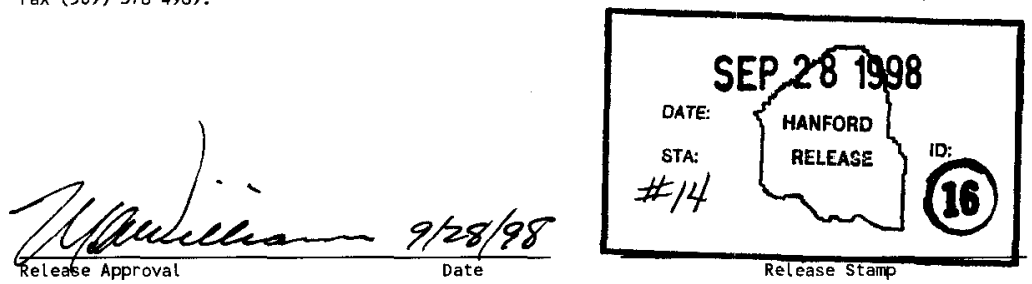

Approved for Public Release 
TEST TITLE: AP-102/104 Retrieval Control System Qualification Test Procedure (OTP) LOCATION: 200-E Area (Building 2721EA)

PROJECT NUMBER: W-211 WORK ORDER A8 5B 161 PROJECT TITLE: W-211. INITIAL TANK RETRIEVAL SYSTEMS (ITRS)

Prepared By

FLUOR DANIEL NORTHWEST, Inc. Rich 7 and. Washington

PROCEDURE APPROVAL

FLUOR DANIEL NORTHWEST (FDNW)

$\begin{array}{cc}\frac{\text { G. A. Block }}{\text { Author }} & \frac{7 / 15 / 98}{\text { Date }} \\ \begin{array}{c}\text { Eric D. Johnson } \\ \text { Checker }\end{array} & \frac{7 / 15 / 98}{\text { Date }} \\ \text { G. A. Block } & \frac{7 / 15 / 98}{\text { Date }}\end{array}$


EXECUTION AND TEST APPROVAL

EXECUTED BY

$\frac{\text { George A. Block /FDNW }}{\text { Test Director (Recorder)/Organization }} \frac{8 / 24 / 98}{\text { Date }} \frac{\text { Eric D. Johnson /FDNW }}{\text { Test Performer/Organization Date }}$

$\frac{\text { Steve M. Dunham /FDNW }}{\text { Test Performer/Organization }} \frac{8 / 24 / 98}{\text { Date }}$

WITNESS

$\frac{\text { Lanny R. Hall /FDNW }}{\text { QA Inspector (Witness)/Organization }} \frac{8 / 24 / 98}{\text { Date }}$

A-E APPROVAL

FLUOR DANIEL NORTHWEST (FDNW)

Without With exceptions

exceptions

resolved

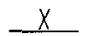

With exceptions

outstanding

George A. Block

Design Engineer

$8 / 24 / 98$

Date

This document, procedure HNF-3334, was performed during the period of $8 / 4 / 98$ through $8 / 24 / 98$. The procedure was signed of $f$ and annotated as the test progressed and as anomalies were identified and resolved. The signed-off version has been retained on file.

The procedure was retyped to incorporate red-lined revisions developed during actual test performance and issued as Revision 0 . In addition, initials were typed into Revision 0 , and Revision 0 does not include the check marks that were entered on the original document in several test matrices; however, the retained original contains all the appropriate check marks and initials.

The performers reviewed the revised procedure against the original annotated procedure, and upon confirmation that Revision 0 accurately reflected the annotations made on the original, resigned Revision 0.

Revision 0 to the procedure is being distributed herewith to communicate the test methodology and provide confirmation that the tested system performs in accordance with design requirements as stated in W211 Description of Operation (D00). Revision E. 


\section{TABLE OF CONTENTS}

Section

PROCEDURE APPROVAL

EXECUTION AND TEST APPROVAL

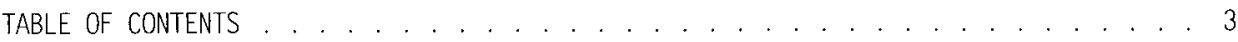

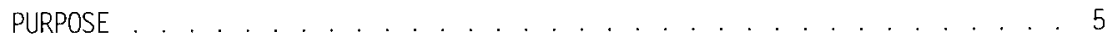

2

REFERENCES

2.1

2.2

DOCUMENTS

DRAWINGS

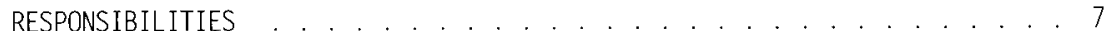

3.1

3.2

3.3

3.4

3.5
GENERAL . . . . . . . . . . . . 7

FDNW PROJECT LEAD ENGINEER (PLE) . . . . . . 7

TEST DIRECTOR . . . . . . . . . 7

WITNESS (PROVIDED BY QUALITY ASSURANCE) . . 8

TEST PERFORMERS . . . . . . . . . . . 9

CHANGE CONTROL

5.1

5.2

6

EXCEPTIONS

6.1

6.2
GENERAL RETEST/RESOLUTION
OCCUPATIONAL SAFETY AND HEALTH . . . . . 9

PERFORMANCE 9

PREREQUISITES, EQUIPMENT/INSTRUMENTS, AND ABBREVIATIONS . . . . . . . 11

7.1

7.2

7.3

7.4

7.5

8 FIELD CONNECTION SIMULATIONS

\section{1}

8.2

8.3

8.4
EQUIPMENT/INSTRUMENTS . . . . . . . . . . . 11

ABBREVIATIONS ............. 11

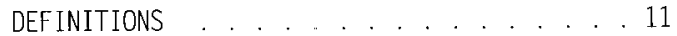

POWER UP RCS SYSTEM _........... 11

GENERAL-SCREEN DEVELOFMENT . . . . . . . . 13

PRESSURE INDICATORS AND ALARMS ...... 16

FLOW INDICATORS AND ALARMS . . . . . . . . 18

TEMPERATURE INDICATORS AND ALARMS .... 21

MOTOR VIBRATION INDICATORS AND ALARMS . . . 26 
ANALOG VOLTAGE INSTRUMENTS . . . . . . . 28

8.7

DISCRETE INPUT SIMULATION . . . . . . . . . . . 29

8.8

COMMAND OUTPUTS

9 VALVE MANUAL CONTROL IN READY MODE

9.1

9.2

READY MODE VALVE MANUAL CONTROL TEST .32

9.3

FLOW CONTROL VALVES . . . . . . . 34

VERIFY AUTO CHECK FOR EACH MODE . . . . . . 34

10 MODE SWITCHING INTERLOCKS

10.1

INTERLOCK MATRIX

10.2

10.3

DOCUMENTATION $\ldots \ldots \ldots$

VALVE ALIGNMENT $\ldots \ldots \ldots$ 
HNF -3334 , Rev 0

1 PURPOSE

The purpose of this Qualification Test Procedure (QTP) is to confirm that the $W$ 211 AP Farm Retrieval Control System (RCS) computer control system has been programmed correctly, and that the two related hardware enclosures have been assembled correctly in accordance with requirements documents, and are ready for installation at the AP tank farm under the auspices of construction specification W-211-AP-C1. After installation, an Acceptance Test Procedure (ATP), similar to this QTP will be performed to test field devices and connections.

\section{REFERENCES}

2.1

DOCUMENTS

DESCRIPTION OF OPERATIONS(OO0), FOR DST 241-AP-102/104 RETRIEVAL, REVISION 0

$2.2 \quad$ DRAWINGS

Performance of this QTP represents checking of the drawings listed below.

H-14-102086. Sh 1, Rev 0

H-14-102086. Sh 2. Rev 0

H-14-102086, Sh 3, Rev 0

H-14-102086, Sh 4, Rev 0

H-14-102086, Sh 5, Rev 0

H-14-102086. Sh 6, Rev 0

H-14-102304, Sh 1, Rev 0

H-14-102304, Sh 2, Rev 0

$H-14-102190$. Sh 2. Rev 0

H-14-102191. Sh 2-7. Rev 0

$H-14-102151$, Sh 1, Rev 0

H-14-102151, Sh 2, Rev 0

H-14-102151, Sh 3, Rev 0

H-14-102151. Sh 4, Rev 0

H-14-102151, Sh 5, Rev 0

H-14-102151, Sh 6, Rev 0

H-14-102151. Sh 7. Rev 0

H-14-102151, Sh 8, Rev 0

H-14-102151, Sh 9, Rev 0

H-14-102151, Sh 10, Rev 0

H-14-102151, Sh 11, Rev 0

H-14-102151, Sh 12, Rev 0

H-14-102151, Sh 13, Rev 0

H-14-102151. Sh 14, Rev 0

H-14-102151. Sh 15, Rev 0

H-14-102151, Sh 16, Rev 0
PIPING/INSTRM P \& ID GENERAL. NOTES \& LEGEND

PIPING/INSTRM P \& ID Pump Pit 02A (WST)

PIPING/INSTRM $P$ \& ID PUMP PITS 02A/02D (WT)

PIPING/INSTRM $P$ \& ID Pump Pit 04A (WST)

PIPING/INSTRM $P$ \& ID PUMP PITS 04A/04D (WT)

PIPING/INSTRM P \& ID PUMP PITS 04A/04D (WT)

PIPING/INSTRM $P$ \& ID SERVICE WATER (RW)

PIPING/INSTM P \& ID DILUENT/FLUSH (CHEMB)

CONNECTION DIAGRAM WT-ENCL-100

CONNECTION DIAGRAM WT-ENCL-1.01

LOGIC DIAGRAM Drawing List \& Notes

LOGIC DIAGRAM HVT MODE

LOGIC DIAGRAM IN2 MODE

LOGIC DIAGRAM IN4 MODE

LOGIC DIAGRAM RTN2 MODE

LOGIC DIAGRAM RTN4 MODE

LOGIC DIAGRAM RTF2 MODE

LOGIC DIAGRAM RTF4 MODE

LOGIC DIAGRAM DIL2 MODE

LOGIC DIAGRAM DIL4 MODE

LOGIC DIAGRAM ITR2 MODE

LOGIC DIAGRAM ITR4 MODE

LOGIC DIAGRAM ITF2 MODE

LOGIC DIAGRAM ITF4 MODE

LOGIC DIAGRAM WT2 MODE

LOGIC DIAGRAM WT4 MODE 
H-14-102151, Sh 17, Rev 0 H-14-102151, Sh 18, Rev 0 H-14-102151, Sh 19, Rev 0 H-14-102151, Sh 20, Rev 0 H-14-102151, Sh 21, Rev 0 H-14-102151, Sh 22, Rev 0 H-14-102151. Sh 23, Rev 0

H-14-102152, Sh 1, Rev 0 H-14-102152, Sh 2, Rev 0 H-14-102152, Sh 3, Rev 0 H-14-102152, Sh 4, Rev 0 H-14-102152, Sh 5, Rev 0 H-14-102152, Sh 6, Rev 0 H-14-102152, Sh 7, Rev 0 $H-14-102152$, Sh 8, Rev 0 $H-14-102152$, Sh 9, Rev 0 H-14-102152, Sh 10, Rev 0 H-14-102152, Sh 11, Rev 0 H-14-102152, Sh 12. Rev 0 H-14-102152, Sh 13, Rev 0 H-14-102152, Sh 14, Rev 0 H-14-102152, Sh 15, Rev 0 H-14-102152. Sh 16. Rev 0 H-14-102152, Sh 17, Rev 0 H-14-102152, Sh 18, Rev 0 H-14-102152, Sh 19, Rev 0 H-14-102152. Sh 20, Rev 0 H-14-102152, Sh 21, Rev 0

H-14-102153, Sh 1, Rev 0 $H-14-102153$, Sh 2, Rev 0 $\mathrm{H}-14-102154$, Sh 1, Rev 0 H-14-102154, Sh 2, Rev 0 $H-14-102155$. Sh 1, Rev 0 $\mathrm{H}-14-102155$, Sh 2, Rev 0 $H-14-102156$, Sh 1, Rev 0 H-14-102157. Sh 1, Rev 0 H-14-102158, Sh 1, Rev 0 H-14-102159, Sh 1, Rev 0

H-14-102165, Sh 1, Rev 0 H-14-102165. Sh 2, Rev 0 $\mathrm{H}-14-102165$, Sh 3, Rev 0 H-14-102165. Sh 4. Rev 0 H-14-102165. Sh 5, Rev 0
LOGIC DIAGRAM PTF2 MODE LOGIC DIAGRAM PTF4 MODE LOGIC DIAGRAM ILD2 MODE LOGIC DIAGRAM ILD4 MODE LOGIC DIAGRAM CSS Batch MODE LOGIC DIAGRAM CSS Cont inuOUS MODE LOGIC DIAGRAM SSD MODE

LOGIC DIAGRAM CHEMB-FCV-131 LOGIC DIAGRAM CHEMB-MOV - 132 LOGIC DIAGRAM WT-MOV-242 LOGIC DIAGRAM WT-MOV-243 LOGIC DIAGRAM WT-MOV-244 LOGIC DIAGRAM WT-MOV-245 LOGIC DIAGRAM WT-MOV-246 LOGIC DIAGRAM WT-MOV-247 LOGIC DIAGRAM WT-MOV-248 LOGIC DIAGRAM WT-FCV-249 LOGIC DIAGRAM WT-MOV-250 LOGIC DIAGRAM WT-MOV-251 LOGIC DIAGRAM WT-MOV-252 LOGIC DIAGRAM WT-MOV-253 LOGIC DIAGRAM WT-MOV-254 LOGIC DIAGRAM WT-MOV-261 LOGIC DIAGRAM WT-MOV-263 LOGIC DIAGRAM CHEMB-LCV-430 LOGIC DIAGRAM RW-MOV-451 LOGIC DIAGRAM MOV POSITION ALARMS LOGIC DIAGRAM MOV POSITIONS SSD

LOGIC DIAGRAM Alarm Interlocks-1 LOGIC DIAGRAM Alarm Interlocks-2 LOGIC DIAGRAM Mixer Pump 001 Control LOGIC DIAGRAM Mixer Pump 001 Turntable LOGIC DIAGRAM Mixer Pump 003 Control LOGIC DIAGRAM Mixer Pump 003 Turntable LOGIC DIAGRAM Transfer Pump 002 Speed Control LOGIC DIAGRAM Transfer Pump 019 Speed Control LOGIC DIAGRAM AP-102 RTD 1 LOGIC DIAGRAM AP-104 RTD 1

LOGIC DIAGRAM Mode Select 1 A LOGIC DIAGRAM Mode Select IB LOGIC DIAGRAM Mode Select IC LOGIC DIAGRAM Mode Select 10 LOGIC DIAGRAM Mode Select 2A 
HNF-3334, Rev 0
$H-14-102165$. Sh 6, Rev 0
LOGIC DIAGRAM Mode Select 2B
H-14-102165, Sh 7, Rev 0 LOGIC DIAGRAM Mode Select $2 C$
H-14-102165, Sh 8, Rev 0 LOGIC DIAGRAM Mode Select 20
H-14-102165, Sh 9, Rev 0 LOGIC DIAGRAM Mode Select 3A
H-14-102165, Sh 10, Rev 0 LOGIC DIAGRAM Mode Select 3B

\section{RESPONSIBILITIES}

GENERAL

Each company or organization participating in this QTP wil1 designate personnel to assume the responsibilities and duties as defined herein for their respective roles. The designees shall become familiar with this QTP and the systems involved to the extent that they can perform their assigned duties.

3.2 FDNW PROJECT LEAD ENGINEER (PLE)

3.2.1 Designates a Test Director.

3.2.2 Acts as 7iaison between the participants in acceptance testing.

3.2.3 Schedules and conducts a pretest kickoff meeting with test participants when necessary.

3.2.4 Signs Execution and Test Approval page when test is complete and accepted.

3.2.5 Signs exception form when all exceptions have been resolved.

3.2.6 Provides a distribution list for the approved and accepted QTP.

\subsection{TEST DIRECTOR}

3.3.1 Coordinates and directs acceptance testing.

3.3.2 Coordinates testing with the Facility Manager.

3.3.3 Distributes the approved testing schedule before start of testing.

3.3.4 Notifies the persons performing and witnessing the test 2 days before the start of testing.

3.3.5 Schedules a dry run when necessary.

3.3.6 Notifies concerned parties when a change is made in the testing schedule. 
3.3.7 Arranges for craft electrician labor as required.

3.3.8 Confirms that field testing and inspection of the system or portion of the system to be tested has been completed.

3.3.9 Stops any test which, in his or her judgement, may cause damage to the system until the problem has been resolved.

3.3.10 After verifying there is no adverse impact, may alter the sequence in which systems or subsystems are tested.

3.3.11 Ensures that required environmental conditions are maintained.

3.3.12 If a test is to be suspended for a period of time, ensures that the system is left in a safe mode.

3.3.13 Before restarting suspended test, reverifies the test prerequisites.

3.3.14 Initiates required changes to the QTP.

3.3.15 Reviews recorded data, discrepancies, and exceptions.

3.3.16 Obtains information or changes necessary to clear or resolve objections during the performance of the test.

3.3.17 Takes necessary action to clear exceptions to the test.

3.3.18 Signs Execution and Test Approval page when test has been performed.

3.3.19 Obtains required signatures on the QTP Master prior to reproduction and distribution.

\subsection{WITNESS (PROVIDED BY QUALITY ASSURANCE)}

3.4.1 Witnesses the tests.

3.4.2 Reviews results of testing.

3.4.3 Assists the Test Director when requested.

3.4.4 Signs Execution and Test Approval page when test has been performed.

3.4.5 Records names of al1 designated personnel on master copy of QTP prior to start of testing. 
HNF -3334 , Rev 0

3.4.6 Records test instrument identification numbers and calibration expiration dates. if applicable.

\section{$3.5 \quad$ TEST PERFORMERS}

(One Test Performer wi 11 operate the Test Set and the other Test Performer wi 11 operate the PLC control system.)

3.5.1 Perform test under direction of the Test Director.

3.5.2 Signs the Execution and Test Approval page.

4 CHANGE CONTROL

Required changes to this QTP must be redlined on the Master copy. The test may continue based on red-7ine markups of the Master copy.

5 EXECUTION

5.1 OCCUPATIONAL SAFETY AND HEALTH

5.1.1 Individuals shall carry out their assigned work in a safe manner in accordance with FDNW Practice 134.653.1010, 4/28/98, to protect themselves and others from undue hazards and to prevent damage to property and environment. Facility line managers shall assure the safety of activities within their areas to prevent injury, property damage. or interruption of operation. Performance of test activities sha11 always include safety and health aspects.

5.1.2 These tests involve working near energized equipment: all procedural requirements for working near energized equipment shall be followed. and an Energized Electrical Work Permit (FDNW Form S-NW-061) sha11 be prepared and processed.

5.1.3 Read and sign the JSA located at the test site.

5.2 PERFORMANCE

Perform the test following the steps and requirements of this procedure.

6 EXCEPTIONS

6.1 GENERAL 
Exceptions to the required test results that cannot be immediately corrected are recorded for future resolution. The procedural step that was not able to be performed is not signed off until it can be performed as initially written or as revised.

Errors/exceptions in the QTP itself may be corrected by redlined changes and/or direct revision of the QTP.

\subsection{RETEST/RESOLUTION}

Record the action taken to resolve- each exception. Action taken may not be the same as planned action.

6.2.1 When action taken results in an acceptable retest, sign and date the appropriate procedural step.

\subsection{ACCURACY/TOLERANCES}

This QTP is a functional test, not a calibration. Therefore, observed analog values are considered acceptable if they are within $\pm 5 \%$ of the values specified in this procedure.

REFER TO SECTION 3.4.6

PRINTED NAME

SIGNATURE

INITIAL
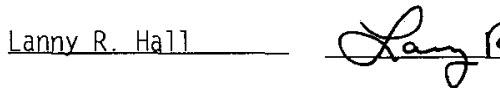

R. Wael $\underline{\mathrm{LH}}$ (Quality Assurance)

Eric D. Johnson
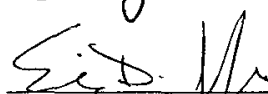
-

Steve Dunham

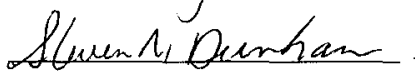
SMD (Test Performer)

George Block

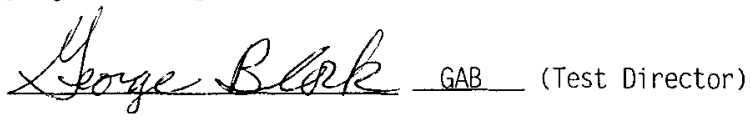


7 PREREQUISITES, EQUIPMENT/INSTRUMENTS, AND ABBREVIATIONS

$7.1 \quad$ EQUIPMENT/INSTRUMENTS

Supplied by Test Operator unless otherwise noted.

7.1.1 Volt-ohmmeter (VOM): Digita1, portable, $0-150 \mathrm{~V} \mathrm{ac} / \mathrm{dc}$.

Instrument No. Fluke 23 Series II Multimeter. S/N 53850912

7.1.2 Current source test set.

Description: Altek-134 S/N 194716

7.1.3 RTD Simulator. Description:

Altek-211 S/N 228751. Biddle Versa-Cal S/N 3148

7.1.4 Test leads with insulated covers for wire clips.

$7.2 \quad$ ABBREVIATIONS

RTD Resistance Temperature Detector

VI Vendor Information

VOM Volt-ohmmeter

$7.3 \quad$ DEFINITIONS

7.3.1 Verify alarms: Verify that an audible signal indicates an alarm condition, the alarm icon on the screen flashes red, moves left to right and the graphic screen (page or window) containing the alarming device pops up when applicable. Verify affected graphic symbol flashes red or yellow as applicable. Close pop-up window and/or click on the alarm navigation button to display alarms screen. Click on the appropriate alarm text to acknowledge. Verify the alarm text has gone to a steady color (red, yellow or blue).

7.3.2 Verify alarm(s) is/are reset: Use the F5 key to show the active alarms and verify the alarm listed is no longer displayed and affected device is no longer flashing red or yellow.

$7.4 \quad$ POWER UP RCS SYSTEM

In this section the RCS system will be logged into and set up for simulated operation. 
HNF-3334, Rev 0

NOTE 1: Figures of screens are contained in Appendix D of Description of Operations for DST 241-AP-102/104 (see attached).

NOTE 2: If the test setup has been previously energized and is presently energized, skip to step 7.5.2.

$\underline{\mathrm{LH}} \quad$ 7.4.1 Turn on all equipment. Verify appropriate power indicators are lighted and computer screens are energized.

\subsubsection{Window's NT Log ON}

Operator Workstation logon

LH 7.4.2.1 On the Operator Workstation, verify that the Window NT Start Up screen is displayed.

LH 7.4.2.2 Press Ctri-Alt-Del at the keyboard of the Operator Workstation.

LH 7.4.2.3 At the Windows NT logon screen type in the User Name, Password, and Domain as obtained from the Test Director.

LH_ 7.4.2.4 After logging on. verify on the Operator Workstation monitor. that the TWRS Home screen is displayed similar to Figure 1 in Appendix 0 .

LH 7.4.2.5 Click on the Retrieval Control tab. Verify that the Retrieval Control screen is displayed (see figure 2 in Appendi X D) and click on the "AP Farm" button to display the AP-102 and -104 RCS Title screen (see figure 3 in Appendix D).

LH 7.4 .2 .6

While the Title Screen is displayed click on the "LOGIN" button or press F3.

L 7.4.2.7 At the CITECT login screen type in the UserName and Password as obtained from the Test Director.

7.4.3 Engineering Workstation logon

$\underline{L}$ ․․‥ 7.1 On the Engineering Workstation. verify that the Window NT Start Up screen is displayed.

IH 7.4.3.2 Press Ctr1-Alt-Del at the keyboard of the Engineering Workstation. 
HNF-3334, Rev 0

LH 7.4.3.3 At the Windows NT logon screen type the UserName, Password, and Domain as directed by the Test Director.

NOTE: During this QTP many of the $1 / 0$ analog inputs wi11 not have external wires connected. Therefore, the I/0 modules will show an "Input Failure" light, and most low level analog alarms will be activated until a simulated input is applied to the specific channel.

Where analog inputs are statically simulated by resistors or resistance bridges, these static devices must be disconnected when applying the dynamic simulations required by this QTP. When the dynamic simulation is complete, the static simulation should be reconnected to reduce the number of active alarms.

7.4.4 RCS Title Screen Login

Screen Login wi 11 be done in this section along with verifying what state or mode the RCS system is currently indicating.

LH 7.4.4.1 Verify the prerequisites of Section 7.4 have been met. If stil1 logged in from section 7.5.2, go to 7.5.4.3.

LH 7.4.4.2 At the Operator Workstation, C1ick the "Login" button or press F 3 and enter the UserName and Password as directed by the Test Director.

LH 7.4.4.3 Press F2 to display the pop-up window menu (see Figure 5 in Appendix D). Click the "Mode Selection" button and verify that the Mode Selection screen is displayed (see Figure 7 in Appendix D).

LH 7.4.4.4 Verify the "Ready" mode is currently selected. The button will be outlined in blue. (If not, operator shall select Ready mode). Close window by clicking on "CLOSE" button, or pressing "END" key.

LH 7.4.4.5 Press F2 to display the pop-up window menu and click the "Process Overview" button. Verify that the process overview screen is displayed (see Figure 4 in Appendix D).

LH 7.4.4.6 Verify that process lines are white (no modes selected).

7.5 GENERAL-SCREEN DEVELOPMENT

This section is to verify and test a11 major screen buttons. keyboard commands and tables when in Ready mode. The Test Director or RCS Operator will step 
HNF-3334, Rev 0

through each screen and verify it functions in Ready mode. No activation or changing of set points will be done in this section. Figures will be used to display what screens should look like when clicked on (see attached Appendix D).

Every operations function which can be activated/selected by clicking with the mouse can also be activated/selected by a function key (not a 11 screens can be displayed by pressing a function key) or moving the focus with the arrow keys and pressing enter (all screens can be displayed with this method). Where possible check both methods of activation/selection in the same step. If not possible. for example, when going from one mode to the next, come back to the step and use the other method of activation/selection. when there are three methods (mouse. arrow keys and function key) try al1 three. Check the box ( $\square$ ) provided in each step when validating the arrow keys, the Function key (when appropriate), and initial the step when validating the mouse click method of activation/selection.

After selecting a screen using one of the three methods, click the close icon button to close the window or click the "last" navigation button (back arrow) to close a futr screen page.

7.5.1 At the Title Screen, Press F2 and verify the new screen pops up:

\section{$\underline{L}$ - 7.5.1.1 "Pop-Up Window Menu" (Figure 5)}

From the Pop-Up Window Menu verify the following screens pop up by moving the focus (the white outline around selectable symbols) with the arrow keys and pressing enter, place a check in box provided next to "Key". Then return to the Pop-Up Window Menu and verify the screens pop-up by pressing the appropriate function key, place a check in the box provided next to "F-Key". Then return to previous screen and verify the screen pops up by using the mouse to click on the selection and then initial the step.

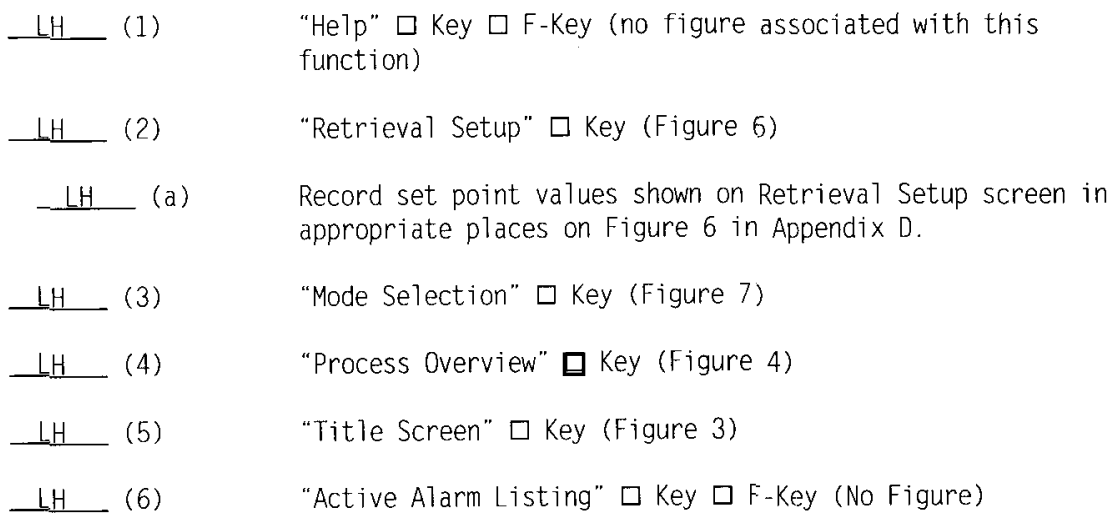




\author{
$\underline{\mathrm{LH}}$ (7) \\ "Alarm Set point" $\square$ Key (Figure 17) \\ $\underline{\mathrm{LH}}(\mathrm{a})$ \\ Verify that alarm set points on the screen are the same as \\ those listed in the steps in section 8 . If the set point \\ values shown on the screen do not agree with those used in \\ Section 8 , enter the Section 8 value on the screen and on \\ figure 17 of Appendix D. \\ $\underline{\mathrm{LH}}(8)$ \\ $\underline{\mathrm{LH}}(9)$ \\ $\underline{\mathrm{LH}}$ - (10) \\ $\underline{\mathrm{LH}}(11)$ \\ $\underline{\mathrm{LH}}$ (12) \\ $\underline{\mathrm{LH}}(13)$ \\ $\underline{\mathrm{LH}}(14)$ \\ $\underline{\mathrm{LH}}(15)$ \\ $\underline{\mathrm{LH}}(16)$ \\ $\underline{\mathrm{LH}}(17)$ \\ $\underline{\mathrm{LH}}-(18)$ \\ $\underline{\mathrm{LH}}$ (19) \\ $\underline{\mathrm{LH}}$ - (20) \\ $\underline{\mathrm{LH}}(21)$ \\ $\mathrm{LH} \quad 7.5 .2$ \\ "Alarm Summary" $\square$ Key $\square$ F-Key (No Figure) \\ “Hardware Alarms" $\square$ Key $\square$ F-Key (No Figure) \\ “Tank 241-AP-102 Overview" $\square$ Key (Figure 9) \\ "Tank 241-AP-104 Overview" $\square$ Key (Figure 10) \\ "Trending" $\square$ Key (Figure 18) \\ “Bypassable Interlock Table” $\square$ Key (Figure 8) \\ "Temp Profile" $\square$ Key (Tank AP-102) (Figure 13) \\ "Temp Profile" $\square$ Key (Tank AP-104) (Figure 14) \\ AP-102 "Mixer Pump P-001 Speed Profile" $\square$ Key (Figure 11) \\ AP-102 "Mixer Pump P-003 Speed Profile" $\square$ Key (Figure 12) \\ "Service Water System" $\square$ Key (Figure 16) \\ "Diluent System" $\square$ Key (Figure 15) \\ "Hardware Overview" $\square$ Key (Figure 19) \\ "Active Interlocks Table" $\square$ Key (Figure 20) \\ Verify that all steps of section 7 have been satisfactorily \\ completed. \\ In ENCL-100 and -101 , close a11 fuses. \\ 8 FIELD CONNECTION SIMULATIONS \\ NOTE: A11 termina 1s and instruments are in WT-ENCL-101, unless otherwise \\ noted.
}


HNF-3334, Rev 0

Acknowledge each alarm after it is verified.

\subsection{PRESSURE INDICATORS AND ALARMS}

NOTES: $\quad$ 1. The input current is given as a percentage of 4-20mA current signal $(0 \%=4 \mathrm{~mA}$ and $100 \%=20 \mathrm{~mA})$.

2. HIGH or LOW alarms will produce a flashing yellow/black border around the value display box, and HIGH/HIGH or LOW/LOW alarms wi17 produce a flashing red/white border around the value display box. and will display as flashing indications on the PLC Interlock Bypass Screen if bypassable and on the Active Interlocks screen if not bypassable.

LH_ 8.1.1 To simulate WT-PIT-259, disconnect wires at PLC 2-1-8, terminals 6 and 7 . Connect $4-20 \mathrm{~mA}$ transmitter simulator. set at $0 \%$ to terminats $6(-)$ and $7(+)$. Then perform the following:

내 $\quad 8.1 .1 .1$

LH $\quad 8.1 .1 .2$

LH_ $\quad 8.1 .1 .3$

LH_ 8.1.1.4

NA

NA

NA

LH__ 8.1.1.8

L
Increase transmitter simulator to $86 \%$. Verify pressure on the Process Overview screen indicates $>255 \mathrm{psig}$. Verify that alarm PAH-259. "Transfer Pump WT-P-002 High Discharge Pressure" alarms.

Increase transmitter simulator to $88.5 \%$. Verify pressure on screen indicates $>265$ psig. Verify that alarm PAHH-259 "Transfer Pump WT-P-002 Hi-Hi Discharge Pressure" a Tarms.

Verify that "TRANSFER PUMP DISCHARGE PRESSURE HI-HI" indicator is flashing on the Interlock screen.

Decrease transmitter simulator to $71.6 \%$. Verify displayed pressure is 215 psig. Verify that alarms PAH-259 and PAHH259 can be reset.

Removed

Removed

Removed

Vary the input current from 0 to $100 \%$ and verify the range of the pressure (psi) indicator on screen (near tank 241-AP102) varies from 0 to 300 psi.

Remove transmitter simulator and reconnect wire PT-259-(+) to terminal 7 and PT-259-(-) to terminal 6 of PLC 2-1-8. 
IH 8.1.2 To simulate WT-PIT-266, disconnect wires at PLC 2-1-8, termina 1s 36 and 37. Connect 4-20mA transmitter simulator, set at $0 \%$ to terminals $36(-)$ and $37(+)$. Then perform the following:

$\mathrm{LH}$ 8.1.2.1

Increase transmitter simulator to $86 \%$. Verify pressure on screen indicates $>255$ psig. Verify that alarm PAH-266. "Transfer Pump WT-P-019 High Discharge Pressure" alarms.

LH $\quad$ 8.1.2.2

Increase transmitter simulator to $88.5 \%$. Verify pressure on screen indicates $>265 \mathrm{psig}$. Verify that alarm PAHH-266 "Transfer Pump WT-P-019 Hi-Hi Discharge Pressure" alarms.

LH 8.1 .2 .3

Verify that "TRANSFER PUMP DISCHARGE PRESSURE HI-HI" indicator is flashing on the Interlock screen.

$\underline{\mathrm{LH}}$ 8.1.2.4

Decrease transmitter simulator to $71.6 \%$. Verify displayed pressure is $215 \mathrm{psig.} \mathrm{Verify} \mathrm{that} \mathrm{alarms} \mathrm{PAH-266} \mathrm{and} \mathrm{PAHH-}$ 266 can be reset.
NA
8.1 .2 .5
Removed
NA
8.1 .2 .6
Removed
NA
8.1.2.7
Removed

$\mathrm{LH} \quad 8.1 .2 .8$

Vary the input current from 0 to $100 \%$ and verify the range of the pressure (psi) indicator on screen (near tank 241-AP104) varies from 0 to 300 psi.

$\mathrm{LH} \quad$ 8.1.2.9

Remove transmitter simulator and reconnect wire PT-266-(+) to terminal 37 and PT-266-(-) to terminal 36 of PLC 2-1-8.

LH 8.1.3 To simulate PIT-271, disconnect wires at PLC 2-1-9, termina1s 2 and 3. Connect $4-20 \mathrm{~mA}$ transmitter simulator, set at $55 \%$ to terminals $2(-)$ and $3(+)$ and reset any existing alarms. Then perform the following:

$\underline{\mathrm{LH}}$ 8.1.3.1

Decrease simulated pressure to 0 psig $(0 \%)$ and increase simulated pressure to $300 \mathrm{psig}(100 \%)$ and verify that the range of the pressure ( $p s i$ ) indicator on screen (near valve WT-MOV-252, approximate center of screen) varies from 0 to 300 psi ( 0 to $100 \%$ ).

LH

Remove transmitter simulator and reconnect wire PT-271-(+) to terminal 3 and PT-271-(-) to terminal 2 of PLC 2-1-9. 
HNF-3334, Rev 0

LH_ 8.1.4 To simulate PIT-452. disconnect wires at PLC 2-1-10, terminals 22 and 23. Connect 4-20mA transmitter simulator, set at $55 \%$ to terminals $22(-)$ and $23(+)$ and reset any existing alarms. Then perform the following:

$\mathrm{LH} \quad$ 8.1.4.1 Decrease simulated pressure to 0 psig $(0 \%)$ and increase simulated pressure to $200 \mathrm{psig}(100 \%)$ and verify that the range of the pressure (psi) indicator on screen varies from 0 to 200 psi (0 to $100 \%)$.

LH 8.1 .4 .2

Remove transmitter simulator and reconnect wire PT-452-(+) to terminal 23 and PT-452-(-) to terminal 22 of PLC 2-1-10.

LH_ 8.1.5 To simulate PIT-123, disconnect wires at PLC 2-1-10, terminals 16 and 17. Connect 4-20mA transmitter simulator, set at $55 \%$ to terminals $16(-)$ and $17(+)$ and reset any existing alarms. Then perform the following:

$\mathrm{LH} \quad$ 8.1.5.1 Decrease simulated pressure to 0 psig $(0 \%)$ and increase simulated pressure to $300 \mathrm{psig}(100 \%)$ and verify that the range of the pressure (psi) indicator on screen varies from 0 to 300 psi (0 to $100 \%$ ).

LH_ 8.1.5.2 Remove transmitter simulator and reconnect wire PIT-123-(+) to terminal 17 and PIT-123-(-) to terminal 16 of PLC 2-1-10.

\subsection{FLOW INDICATORS AND ALARMS}

Refer to note 2 in paragraph 8.1 above.

LH 8.2.1 To simulate FIT-258, connect 4-20mA transmitter simulator, set at $50 \%$ to TB-6 terminals $1(+)$ and $2(-)$. Then perform the following:

LH 8.2.1.1 Disable PLC address 004575 and set to "1." Verify that transfer pump WT-P-002 is "on", (symbol is green).

$\mathrm{LH} \quad$ 8.2.1.2 Decrease simulated flow to $60 \mathrm{gpm}(30 \%)$ and verify that a larm FAL-258 "Transfer Pump WT-P-002 Low Discharge Flow" alarms.

LH 8.2 .1 .3

Increase simulated flow to $110 \mathrm{gpm}$ (55\%) and verify that alarm FAL-258 can be reset.

$\mathrm{LH} \quad 8.2 .1 .4$

Verify that the flow (gpm) indicator on screen (near tank 241-AP-102) varies from 0 to $200 \mathrm{gpm}$ ( 0 to $100 \%$ ). 
HNF-3334, Rev 0

LH 8.2.1.5 Set PLC address 004575 to " 0 ", and enable address. Verify that the transfer pump is "off". (symbol is gray).

$\mathrm{LH}$ 8.2.1.6 Disconnect and remove transmitter simulator.

LH_ 8.2.2 To simulate FIT-264, connect 4-20mA transmitter simulator, set at 50\% to TB-6 terminals $22(+)$ and $23(-)$. Then perform the following:

LH 8.2.2.1 Disable PLC address 004591 and set to "1." Verify that transfer pump WT-P-019 is "on", (symbol is green).

LH___ 8.2.2.2 Decrease simulated flow to $<60 \mathrm{gpm}(29.5 \%)$ and verify that alarm FAL-264 "Transfer Pump WT-P-019 Low Discharge Flow" alarms.

$\mathrm{LH} \quad$ 8.2.2.3 Increase simulated flow to $110 \mathrm{gpm}(55 \%)$ and verify that alarm FAL-264 can be reset.

_ 241-AP-104) varies from 0 to $200 \mathrm{gpm}$ (0 to $100 \%$ ).

LH 8.2.2.5 Set PLC address 004591 to "0", and enable address. Verify that the transfer pump is "off". (symbol is gray).

LH 8.2.2.6 Disconnect and remove transmitter simulator.

LH $\quad 8.2 .3$ To simulate FIT-270, connect 4-20mA transmitter simulator, set at $50 \%$ to TB-6 terminals $28(+)$ and $29(-)$. Then perform the following:

LH 8.2.3.1 Vary the simulated flow from $0 \%$ to $100 \%$, and verify that flow indicator FI-270 varies from 0 to $200 \mathrm{gpm}$.

L

LH 8.2.3.3 Reset FQI-270 to 0 using Modsoft if necessary.

$\mathrm{LH} \quad$ 8.2.3.4 Increase simulated flow to $200 \mathrm{gpm}(100 \%)$ and verify that FQI-270 begins to accumulate gallons at a rate of $200 \mathrm{gpm}$ on Modsoft. Run for 5 minutes and verify display on overview screen has accumulated 1000 gallons.

$\mathrm{LH} \quad$ 8.2.3.5 Decrease simulated flow to $0 \mathrm{gpm}(0 \%)$ and verify that FQI270 stops accumulating, and remains constant. 
$\underline{\mathrm{LH}}$ 8.2.3.6 Disconnect and remove transmitter simulator.

LH 8.2.4 To simulate FIT-455, connect 4-20mA transmitter simulator, set at $50 \%$ to TB- 6 terminals $55(+)$ and $56(-)$. Then perform the following:

LH 8.2.4.1 Vary the simulated flow from $0 \%$ to $100 \%$, and verify that flow indicator FI-455 varies from 0 to $100 \%$ ( 0 to $200 \mathrm{gpm}$ ).

LH $\quad$ 8.2.4.2 Set the flow to $0 \%$

LH_ 8.2.4.3 Reset FQI-455 to 0 using Modsoft.

LH 8.2.4.4 Increase simulated flow to $200 \mathrm{gpm}$ (100\%) and verify that FQI-455 begins to accumulate galTons at a rate of $200 \mathrm{gpm}$ on Modsoft. Run for 5 minutes and verify display on overview screen has accumulated 1000 gallons.

LH 8.2.4.5 Decrease simulated flow to $0 \mathrm{gpm}(0 \%)$ and verify that FQI455 stops accumulating, and remains constant.

$\mathrm{LH}$ 8.2.4.6 Disconnect and remove transmitter simulator.

LH 8.2.5 To simulate FIT-122, connect 4-20mA transmitter simulator, set at $50 \%$ to TB-6 terminals $58(+)$ and $59(-)$. Then perform the following:

LH_ 8.2.5.1 Vary the simulated flow from $0 \%$ to $100 \%$, and verify that flow indicator FI-122 varies from 0 to $100 \%$ ( 0 to $200 \mathrm{gpm}$ ).

LH 8.2.5.2 Set the flow to $0 \%$

LH 8.2.5.3 Reset FQI-122 to 0 using Modsoft if necessary.

LH_ 8.2.5.4 Increase simulated flow to $200 \mathrm{gpm}(100 \%)$ and verify that FQIC-122 begins to accumulate gallons at a rate of $200 \mathrm{gpm}$.

LH 8.2.5.5 Decrease simulated flow to $0 \mathrm{gpm}(0 \%)$ and verify that FQIC122 stops accumulating, and remains constant.

L 8.2.5.6 Disconnect and remove transmitter simulator.

LH 8.2.6 To simuTate FIT-456, connect 4-20mA transmitter simulator, set at $50 \%$ to TB-6 termina $7 \mathrm{~s} 67(+)$ and $68(-)$. Then perform the following: 
$1 \mathrm{H}$

8.2.6.1 Vary the simulated flow from $0 \%$ to $100 \%$, and verify that flow indicator FI-456 varies from 0 to $100 \%$ (0 to $200 \mathrm{gpm}$ ).

$\underline{\mathrm{LH}}$ 8.2.6.2 Disconnect and remove transmitter simulator.

LH 8.2.7 To simulate FIT-129, connect 4-20mA transmitter simulator, set at 50\% to TB-6 terminals $106(+)$ and $107(-)$. Then perform the following:

$\mathrm{LH} \quad$ 8.2.7.1 Vary the simulated flow from $0 \%$ to $100 \%$, and verify that flow indicator FI-129 varies from 0 to $100 \%$ ( 0 to $100 \mathrm{gpm}$ ).

$\mathrm{LH}$ _ 8.2.7.2 Disconnect and remove transmitter simulator.

8.3 TEMPERATURE INDICATORS AND ALARMS

Refer to note 2 in paragraph 8.1 above.

LH_ 8.3.1 To simulate TE-204, remove $110 \Omega$ resistor, and connect RTD simulator, set at $32^{\circ} \mathrm{F}$. to TB-7 terminals 6 and 7 . Then perform the following:

$\mathrm{LH}$ 8.3.1.1 Increase simulated temperature to $>275^{\circ} \mathrm{F}$ and verify that a1arm TAH-204 "Mixer Pump AP-102 WST-P-001 Motor Winding High Temperature" alarms.

$\mathrm{LH} \quad$ 8.3.1.2 Increase simulated temperature to $>293^{\circ} \mathrm{F}$ and verify that alarm TAHH-204 "Mixer Pump AP-102 WST-P-001 Motor Winding $\mathrm{Hi}-\mathrm{Hi}$ Temperature" alarms.

\section{NA $\quad$ 8.3.1.3 Removed}

L.H 8.3.1.4 Decrease simulated temperature to $200^{\circ} \mathrm{F}$ and verify that alarms TAH-204 and TAHH-204 can be reset.

LH 8.3.1.5 Disconnect RTD simulator. Replace resistor at terminals 6 and 7.

LH 8.3.2 To simulate TE-203, remove $110 \Omega$ resistor, and connect RTD simulator. set at $32^{\circ} \mathrm{F}$, to TB-7 terminals 2 and 3 . Then perform the following:

$\mathrm{LH} \quad$ 8.3.2.1 Increase simulated temperature to $>185^{\circ} \mathrm{F}$ and verify that alarm TAH-203 "Mixer Pump AP-102 WST-P-001 Upper Bearing High Temperature" alarms. 
$\mathrm{LH} \quad$ 8.3.2.2 Increase simulated temperature to $>203{ }^{\circ} \mathrm{F}$ and verify that alarm TAHH-203 "Mixer Pump AP-102 WST-P-001 Upper Bearing Hi-Hi Temperature" alarms.

\section{NA 8.3.2.3 Removed}

LH_ 8.3.2.4 Decrease simulated temperature to $80^{\circ} \mathrm{F}$ and verify that alarms TAH-203 and TAHH-203 can be reset.

LH_ 8.3.2.5 Remove RTD simulator and replace temporary resistor at terminals 2 and 3.

LH_ 8.3.3 To simulate TE-205, remove $110 \Omega$ resistor, and connect RTD simulator, set at $32{ }^{\circ} \mathrm{F}$, to TB-7 terminals 10 and 11 . Then perform the following:

LH_ 8.3.3.1 Increase simulated temperature to $>185^{\circ} \mathrm{F}$ and verify that alarm TAH-205 "Mixer Pump AP-102 WST-P-001 Lower Bearing High Temperature" alarms.

$\llcorner H \quad 8.3 .3 .2$

Increase simulated temperature to $>203^{\circ} \mathrm{F}$ and verify that alarm TAHH-205 "Mixer Pump AP-102 WST-P-001 Lower Bearing $\mathrm{Hi}-\mathrm{Hi}$ Temperature" alarms.

NA_ 8.3.3.3 Removed

LH_ 8.3.3.4 Decrease simulated temperature to $80^{\circ} \mathrm{F}$ and verify that alarms TAH-205 and TAHH-205 can be reset.

LH 8.3.3.5 Remove RTD simulator and replace temporary resistor at termina $1 \mathrm{~s} 10$ and 11 .

LH_ 8.3.4 To simulate TE-216, remove $110 \Omega$ resistor, and connect RTD simulator, set at $32^{\circ} \mathrm{F}$, to TB-7 terminals 23 and 24 . Then perform the following:

LH_ 8.3.4.1 Increase simulated temperature to $>275^{\circ} \mathrm{F}$ and verify that alarm TAH-216 "Mixer Pump AP-104 WST-P-003 Motor Winding High Temperature" alarms.

LH_ 8.3.4.2 Increase simulated temperature to $>293^{\circ} \mathrm{F}$ and verify that alarm TAHH-216 "Mixer Pump AP-104 WST-P-003 Motor Winding $\mathrm{Hi}-\mathrm{Hi}$ Temperature" alarms.

NA 8.3.4.3 Removed 
HNF-3334, Rev 0

$\mathrm{LH} \quad$ 8.3.4.4 Decrease simulated temperature to $80^{\circ} \mathrm{F}$ and verify that alarms TAH-216 and TAHH-216 can be reset.

LH_ 8.3.4.5 Remove RTD simulator and replace temporary resistor at terminals 23 and 24.

LH_ 8.3.5 To simulate TE-215, remove $110 \Omega$ resistor and connect RTD simulator, set at $32^{\circ} \mathrm{F}$, to TB-7 terminals 19 and 20 . Then perform the following:

LH 8.3.5.1 Increase simulated temperature to $>185^{\circ} \mathrm{F}$ and verify that a larm TAH-215 "Mixer Pump AP-104 WST-P-003 Upper. Bearing High Temperature" alarms.

$\underline{L H} \quad 8.3 .5 .2$

Increase simulated temperature to $>203^{\circ} \mathrm{F}$ and verify that alarm TAHH-215 "Mixer Pump AP-104 WST-P-003 Upper Bearing $\mathrm{Hi}$-Hi Temperature" alarms.

$\underline{N A}$ 8.3.5.3 Removed

LH_ 8.3.5.4 Decrease simulated temperature to $80^{\circ} \mathrm{F}$ and verify that alarms TAH-215 and TAHH-215 are reset.

$\mathrm{LH}$ 8.3.5.5 Remove RTD simulator and replace temporary resistor at terminals 19 and 20 .

LH_ 8.3.6 To simulate TE-217, remove $110 \Omega$ resistor and connect RTD simulator, set at $32^{\circ} \mathrm{F}$, to TB-7 terminals 27 and 28 . Then perform the following:

$\underline{\mathrm{LH}} \quad 8.3 .6 .1$

Increase simulated temperature to $>185^{\circ} \mathrm{F}$, and verify that alarm TAH-217 "Mixer Pump AP-104 WST-P-003 Lower Bearing High Temperature" alarms.

LH $\quad$ L 8.3 .6 .2

Increase simulated temperature to $>203^{\circ} \mathrm{F}$ and verify that alarm TAHH-217 "Mixer Pump AP-104 WST-P-003 Lower Bearing $\mathrm{Hi}-\mathrm{Hi}$ Temperature" alarms.

NA_ 8.3.6.3 Removed

$\mathrm{LH} \quad$ 8.3.6.4 Decrease simulated temperature to $80^{\circ} \mathrm{F}$ and verify that alarms TAH-217 and TAHH-217 are reset.

LH_ 8.3.6.5 Remove RTD simulator and replace temporary resistor at terminals 27 and 28. 
HNF-3334, Rev 0

LH 8.3 .7 To simulate TE-277, remove $110 \Omega$ resistor and connect RTD simulator, set at $32{ }^{\circ} \mathrm{F}$, to TB-7 terminals 36 and 37 . Then perform the following:

$\mathrm{LH} \quad$ 8.3.7.1 Increase simulated temperature to $>275^{\circ} \mathrm{F}$ and verify that alarm TAH-277 "Transfer Pump AP-102 WT-P-002 Motor Winding High Temperature" alarms.

LH_ 8.3.7.2 Increase simulated temperature to $>293^{\circ} \mathrm{F}$ and verify that alarm TAHH-277 "Transfer Pump AP-102 WT-P-002 Motor Winding $\mathrm{Hi}$-Hi Temperature" alarms.

$\mathrm{LH}$ _ 8.3.7.3 Verify "Transfer Pump Motor Winding Temp Hi-Hi" indicator is flashing on the Interlock screen.

LH 8.3.7.4 Decrease simulated temperature to $80^{\circ} \mathrm{F}$ and verify that aiarms TAH-277 and TAHH-277 can be reset.

LH 8.3.7.5 Remove RTD simulator and replace temporary resistor at terminals 36 and 37 .

LH 8.3.8 To simulate TE-274, remove $110 \Omega$ resistor and connect RTD simulator. set at $32^{\circ} \mathrm{F}$, to TB-7 terminals 40 and 41 . Then perform the following:

$\mathrm{LH}$ 8.3.8.1 Increase simulated temperature to $>275^{\circ} \mathrm{F}$ and verify that alarm TAH-274 "Transfer Pump AP-104 WT-P-019 Motor Winding High Temperature" alarms.

LH 8.3.8.2 Increase simulated temperature to $>293^{\circ} \mathrm{F}$ and verify that alarm TAHH-274 "Transfer Pump AP-104 WT-P-019 Motor Winding $\mathrm{Hi}-\mathrm{Hi}$ Temperature" alarms.

$\underline{\mathrm{LH}} \quad$ 8.3.8.3

Verify "Transfer Pump Motor Winding Temp $\mathrm{Hi}-\mathrm{Hi}$ " indicator is flashing on the Interlock screen.

LH 8.3.8.4

Decrease simulated temperature to $80^{\circ} \mathrm{F}$ and verify that alarms TAH-274 and TAHH-274 can be reset.

$\mathrm{LH} \quad$ 8.3.8.5

Remove RTD simulator and replace temporary resistor at termina 1540 and 41.

$\mathrm{LH} \quad 8.3 .9$ To simulate TIT-120, remove $2.4 \mathrm{~K} \Omega$ resistor between terminals 70 and 74 on TB-6, and connect 4-20mA transmitter simulator, set at 45\%. to TB-6 terminals $73\left(_{-}\right)$and $74(+)$. Then perform the following: 
HNF-3334, Rev 0

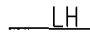

8.3.9.1

L

$\stackrel{\mathrm{LH}}{-}$ 8.3.9.3

LH $\quad$ - 8.3.9.4

L

$\stackrel{\mathrm{LH}}{-} \quad 8.3 .10$

L 내 $\quad 8.3 .10 .1$

$\underline{L} \quad$ 8.3.10.2

$\stackrel{\mathrm{LH}}{-} \quad 8.3 .10 .3$

LH_ 8.3.10.4

$\underline{\mathrm{LH}} \quad 8.3 .10 .5$

$\underline{\mathrm{LH}} \quad 8.3 .11$

$-\underline{L H} \quad 8.3 .11 .1$

L vary the simulated temperature from $45 \%\left(140^{\circ} \mathrm{F}\right)$ to $>50 \%$ $\left(>150^{\circ} \mathrm{F}\right)$, and verify TAH-120 alarms.

Vary the simulated temperature from $50 \%\left(150^{\circ} \mathrm{F}\right)$ to $>55 \%$ $\left(>160^{\circ} \mathrm{F}\right)$, and verify TAHH-120 alarms.

Vary the simulated temperature from $55 \%\left(160^{\circ} \mathrm{F}\right)$ to $<40 \%$ $\left(<130^{\circ} \mathrm{F}\right)$, and verify TAL-120 alarms.

Vary the simulated temperature from $40 \%\left(130^{\circ} \mathrm{F}\right)$ to $<35 \%$ $\left(<120^{\circ} \mathrm{F}\right)$, and verify TALL -120 alarms.

Remove transmitter simulator, and reconnect resistor between termina 7570 and 74.

To simulate TIT-124, remove $2.4 \mathrm{~K} \Omega$ resistor between terminals 76 and 80 on TB-6, and connect 4-20mA transmitter simulator, set at $45 \%$, to TB-6 terminals $79(-)$ and $80(+)$. Then perform the following:

Vary the simulated temperature from $45 \%\left(140^{\circ} \mathrm{F}\right)$ to $>50 \%$ $\left(>150^{\circ} \mathrm{F}\right)$, and verify TAH-124 alarms.

Vary the simulated temperature from $50 \%\left(150^{\circ} \mathrm{F}\right)$ to $>55 \%$ $\left(>160^{\circ} \mathrm{F}\right)$, and verify $\mathrm{TAHH}-124$ a larms.

Vary the simulated temperature from $55 \%\left(160^{\circ} \mathrm{F}\right)$ to $<40 \%$ $\left(<130^{\circ} \mathrm{F}\right)$, and verify TAL-124 alarms.

Vary the simulated temperature from $40 \%\left(130^{\circ} \mathrm{F}\right)$ to $<35 \%$ $\left(<120^{\circ} \mathrm{F}\right)$, and verify TALL-124 alarms.

Remove transmitter simulator, and reconnect resistor between terminals 76 and 80 .

To simulate TIT-457, remove $2.4 \mathrm{~K} \Omega$ resistor between terminals 82 and 86 on TB-6. and connect 4-20mA transmitter simulator, set at $50 \%$, to TB-6 terminals $85(-)$ and $86(+)$. Then perform the following:

Vary the simulated temperature from $0 \%$ to $100 \%$, and verify TI-457 varies from 50 to $250^{\circ} \mathrm{F}$.

Remove transmitter simulator, and reconnect resistor between terminals 82 and 86 . 
HNF-3334, Rev 0

\subsection{MOTOR VIBRATION INDICATORS AND ALARMS}

NOTE: Switch to "TANK 241-AP-102 Overview" screen for this portion of the test.

LH_ 8.4.1 To simulate VT-206, connect transmitter simulator, set at $4 \mathrm{~mA}$, to TB-6 terminals $16(+)$ and $17(-)$. Then perform the following:

LH 8.4.1.1 Increase simulated vibration to $>2.5 \mathrm{mi} / \mathrm{s}(>8 \mathrm{~mA})$ and verify that alarm VAH-206 "Mixer Pump WST-P-001 Upper Bearing High Vibration" alarms.

$\mathrm{LH}$ 8.4.1.2 Increase simulated vibration to $>3 \mathrm{mi} 1 \mathrm{~s}(>8.8 \mathrm{~mA})$ and verify that alarm VAHH-206 "Mixer Pump WST-P-001 Upper Bearing HiHi Vibration" alarms.

NA 8.4.1.3 Removed

LH_ 8.4.1.4 Vary the input simulation from 0 to $100 \%$ and verify that Mixer Pump WST-P-001: Motor Vibration: Upper indicator varies from 0 to $10 \mathrm{mi} 1 \mathrm{~s}(4-20 \mathrm{~mA})$. Disconnect transmitter simulator.

LH 8.4.2 To simulate VT-207. connect transmitter simulator. set at $4 \mathrm{~mA}$, to TB-6 terminals $19(+)$ and $20\left(^{-}\right)$. Then perform the following:

$\mathrm{LH} \quad$ 8.4.2.1 Increase simulated vibration to $>2.5 \mathrm{mi} 1 \mathrm{~s}(>8 \mathrm{~mA})$ and verify that alarm VAH-207 "Mixer Pump WST-P-001 Lower Bearing High Vibration" alarms.

LH 8.4.2.2 Increase simulated vibration to $>3 \mathrm{mi} 5(>8.8 \mathrm{~mA})$ and verify that alarm VAHH-207 "Mixer Pump WST-P-001 Lower Bearing HiHi vibration" alarms.

NA 8.4.2.3 Removed

LH 8.4.2.4 Vary the input simulation from 0 to $100 \%$ and verify that Mixer Pump 001: Motor Vibration: Lower indicator varies from 0 to $10 \mathrm{mi}$ is $(4-20 \mathrm{~mA})$. Disconnect transmitter simulator.

NOTE: Switch to "Tank 241-AP-104 Overview" screen for this portion of the test.

LH 8.4.3 To simulate VT-218, connect simulator, set at $4 \mathrm{~mA}$, to TB-6 terminals $49(+)$ and $50(-)$. Then perform the following: 
HNF-3334, Rev 0

LH 8.4.3.1 Increase simulated vibration to $>2.5 \mathrm{mils}(>8 \mathrm{~mA}$ ) and verify that alarm VAH-218 "Mixer Pump WST-P-003 Upper Bearing High Vibration" alarms.

LH_ 8.4.3.2 Increase simulated vibration to $>3 \mathrm{mi} 7 \mathrm{~s}(>8.8 \mathrm{~mA})$ and verify that alarm VAHH-218 "Mixer Pump WST-P-003 Upper Bearing HiHi Vibration" alarms.

NA 8.4.3.3 Removed

LH 8.4.3.4 Vary the input simulation from 0 to $100 \%$ and verify that Mixer Pump WST-P-003: Motor Vibration: Upper indicator varies from 0 to $10 \mathrm{mi} 1 \mathrm{~s}$ (4-20 mA). Disconnect transmitter simulator.

LH 8.4.4 To simulate VT-219, connect transmitter simulator, to TB-6 terminals $52(+)$ and $53(-)$. Then perform the following:

$\mathrm{LH} \quad$ 8.4.4.1 Increase simulated vibration to $>2.5 \mathrm{mi} 1 \mathrm{~s}(>8 \mathrm{~mA})$ and verify that alarm VAH-219 "Mixer Pump WST-P-003 Lower Bearing High Vibration" alarms.

LH 8.4.4.2 Increase simulated vibration to $>3 \mathrm{mils}(>8.8 \mathrm{~mA})$ and verify that alarm VAHH-219 "Mixer Pump WST-P-003 Lower Bearing HiHi Vibration" alarms.

NA 8.4.4.3 Removed

$\underline{\mathrm{LH}}$ 8.4.4.4 Vary the input simulation from 0 to $100 \%$ and verify that Mixer Pump WST-P-003: Motor Vibration: Lower indicator varies from 0 to $10 \mathrm{mi} 1 \mathrm{~s}(4-20 \mathrm{~mA})$. Disconnect transmitter simulator.

8.5 LIQUID LEVEL and WINCH POSITION INSTRUMENTS

LH_ 8.5.1 To simulate LIT-126, connect 4-20mA transmitter simulator, set at $50 \%$, to TB-6, terminals $100(+)$ and $101(-)$. Then perform the following:

LH 8.5.1.1 Verify $L I-126$ indicates 60 inches $+/-1$ inch.

LH 8.5.1.2 Increase simulated level to $>119 "(100 \%)$ and verify that alarm LAH-126. "Diluent/Flush Tank HI Level" alarms. 
HNF-3334, Rev 0

LH_ 8.5.1.3 Decrease simulated level to 24 " (20\%) and verify hi level alarm can be reset and LAL-126 "Diluent/Flush Tank Low Level" alarms.

LH_ 8.5.1.4 Decrease simulated leve1 to $16^{\prime \prime}$ (13\%) and verify LALL-126 "Diluent/Flush Tank Lo-Lo Level" alarms.

L from 0 " to 120 ".

LH_ 8.5.1.6 Remove transmitter simulator.

\subsection{ANALOG VOLTAGE INSTRUMENTS}

LH_ 8.6.0.1 To simulate ZT-131, rotate the potentiometer located on the test set box. ful1 $\mathrm{CCW}$ to full $\mathrm{CW}$. Verify $\mathrm{ZI}-131$ varies from $0 \%$ to $100 \%$ open.

$\underline{N A}$ 8.6.0.2 Removed

$\mathrm{LH}$ - 8.6.0.3 Leave potentiometers at mid position.

LH 8.6.1 To simulate ZT-262, connect 4-20mA transmitter simulator, set at $50 \%$ to TB-6 terminals $13(+)$ and $14(-)$. Then perform the following:

LH 8.6.1.1 Vary the simulated elevation from $0 \%$ to $100 \%$, and verify that position indicator ZT-262 on "Tank 241-AP-102 Overview" screen varies from $0 "$ to $240 "$.

$\underline{\mathrm{LH}}$ 8.6.1.2 Disconnect and remove transmitter simulator.

LH_ 8.6.2 To simulate ZT-268, connect 4-20mA transmitter simulator, set at $50 \%$ to TB-6 terminals $46(+)$ and $47(-)$. Then perform the following:

$\mathrm{LH}$ - 8.6.2.1 Vary the simulated elevation from $0 \%$ to $100 \%$, and verify that position indicator ZI-268 on "Tank 241-AP-104 Overview" screen varies from $0 "$ to $240 "$.

LH 8.6.2.2 Disconnect and remove transmitter simulator. 


\subsection{DISCRETE INPUT SIMULATION}

For each of the listed inputs. jumper the indicated terminals, verify the specified alarm, acknowledge the alarm, remove the jumper, and reset the alarm.

\begin{tabular}{|c|c|c|c|c|}
\hline INITIALS & DEVICE & $\mathrm{TB}$ & TERMINALS & ALARM ACTION \\
\hline \multicolumn{5}{|l|}{ ENCL - 100} \\
\hline $\mathrm{L}_{\mathrm{L}} \mathrm{H}$ & EDS-XA-101 & 2 & $1 \& 21$ & LOSS OF POWER \\
\hline _L & MPS-001 & 2 & $1 \& 22$ & MPS SHUTDOWN \\
\hline LH_ & RIAS-125A & 2 & $1 \& 23$ & RADIATION ALARM CHANNEL 125 \\
\hline $\mathrm{LH}_{-}$ & RXS-125A & 2 & $1 \& 24$ & RAD CHANNEL 125 FAILURE \\
\hline LH & RIAS-126A & 2 & $1 \& 25$ & RADIATION ALARM CHANNEL 126 \\
\hline LH_ & RXS-126A & 2 & $1 \& 26$ & RAD CHANNEL 126 FAILURE \\
\hline L $\mathrm{LH}$ & RAIS-127A & 2 & $1 \& 27$ & RADIATION ALARM CHANNEL 127 \\
\hline L $\mathrm{LH}$ & RXS-127A & 2 & $1 \& 28$ & RAD CHANNEL 127 FAILURE \\
\hline L $\mathrm{LH}$ & LDS - 282 & 2 & $1 \& 30$ & DILUENT ENCASEMENT LEAK \\
\hline L & LDS-284/285 & 2 & $1 \& 31$ & DILUENT ENCASEMENT LEAK \\
\hline LH & LDS-127 & 2 & $1 \& 34$ & DILUENT FLUSH PIT LEAK \\
\hline LH & LDS - 281/283 & 2 & $1 \& 29$ & TRANSFER LINE LEAK \\
\hline L & LDS-286 & 2 & $1 \& 32$ & CAUSTIC PAD SUMP LEVEL \\
\hline L $\mathrm{LH}_{-}$ & LOS-287A/B & 2 & $1 \& 33$ & PUMP PIT 04D LEAK \\
\hline \multicolumn{5}{|l|}{ ENCL - 101} \\
\hline L ${ }^{H}$ & PSH-276 & 4 & $46 \& 47$ & RUPTURE DISK FAILURE \\
\hline${ }_{2} \mathrm{LH}$ & PSL-280 & 4 & $48 \& 49$ & LOW NITROGEN PRESSURE \\
\hline L & FSH-260 & 4 & $50 \& 51$ & HIGH NITROGEN FLOW \\
\hline $\mathrm{LH}_{-}$ & PSH-275 & 4 & $110 \& 111$ & RUPTURE DISK FAILURE \\
\hline $\mathrm{LH}_{-}$ & PSL - 281 & 4 & $112 \& 113$ & LOW NITROGEN PRESSURE \\
\hline $\mathrm{LH}_{-}$ & FSH-261 & 4 & $114 \& 115$ & HIGH NITROGEN FLOW \\
\hline $\mathrm{LH}_{-}$ & LSH-126 & 4 & $168 \& 169$ & DILUENT TANK HI HI LEVEL \\
\hline
\end{tabular}


HNF-3334, Rev 0

\begin{tabular}{|l|l|l|l|l|}
\hline INITIALS & DEVICE & TB & \multicolumn{1}{|c|}{ TERMINALS } & \multicolumn{1}{|c|}{ ALARM ACTION } \\
\hline LH & TSL-459 & 4 & $170 \& 171$ & RAW WATER ENCLOSURE LOW TEMP \\
\hline LH & PDISH-451 & 4 & $188 \& 189$ & RAW WATER STRAINER HIGH DELTA P \\
\hline LH & PSL -125 & 4 & $197 \& 198$ & LOW SEAL WATER PRESSURE \\
\hline LH & PSL-126 & 4 & $199 \& 200$ & LOW SEAL WATER PRESSURE \\
\hline LH & PDISH-454 & 4 & $201 \& 202$ & 75 mU FILTER HIGH DELTA P \\
\hline LH & PDISH-456 & 4 & $203 \& 204$ & 50 mU FILTER HIGH DELTA P \\
\hline LH & TSL-453 & 4 & $205 \& 206$ & SERVICE WATER ENCLOSURE LOW TEMP \\
\hline LH & TSL-273 & NA & N0 $1 \&$ C & ENCLOSURE TEMP HI \\
\hline LH & TSL-273 & NA & NO $3 \&$ C & ENCLOSURE TEMP LO \\
\hline
\end{tabular}

\subsection{COMMAND OUTPUTS}

LH_ 8.8.1 Confirm no continuity between TB-4 terminals $192 \& 193$.

LH_ 8.8.2 On the HMI screen, click CHEMB-P-002 START button.

LH_ 8.8.3 Confirm continuity between TB-4, terminals 192 \& 193. and no continuity between terminals $193 \& 194$.

LH_ 8.8.4 On the HMI screen, click CHEMB-P-002 STOP button.

$\mathrm{LH}$ _ 8.8.5 Confirm continuity between TB-4. terminals 193 \& 194.

LH_ 8.8.6 On the tank 241-AP-102 overview screen, click the WINCH POSITION UP arrow, and hold down.

LH_ 8.8.7 Confirm 110-120 vac between TB-4, terminals 53 \& 54.

LH_ 8.8.8 On the tank 241-AP-102 overview screen, click the WINCH POSITION DOWN arrow, and hold down.

LH_ 8.8.9 Confirm 110-120 vac between TB-4, terminals 52 \& 54 .

$\mathrm{LH}$ 8.8.10 On the tank 241-AP-104 overview screen, click the WINCH POSITION UP arrow, and hold down.

LH 8.8.11 Confirm 110-120 vac between TB-4, terminals 117 \& 118. 
LH 8.8 .12 On the tank 241-AP-104 overview, click the WINCH POSITION DOWN arrow and hold down.

LH - 8.8.13 Confirm 110-120 vac between TB-4, terminals 116 \& 118.

LH 8.8.14 On the SERVICE WATER SYSTEM overview screen. click the STRAINER MOTOR button.

LH 8.8.15 Confirm 110-120 vac between TB-4, termina7s 195 \& 196.

$\mathrm{LH}$ 8.8.16 $\mathrm{Click}$ the strainer motor button again, and confirm $<15$ vac at terminals 195 \& 196. 
9 VALVE MANUAL CONTROL IN READY MODE

Ready (RDY) is the default mode with no active modes selected. Equipment status including valve positions and current process parameters are displayed.

9.1 READY MODE VALVE MANUAL CONTROL TEST

Use the READY MODE VALVE CONTROL TEST table by proceeding through each step, shown in left hand column. Then proceed to the next position and then to the next 7 isted valve.

Sign the READY MODE VALVE CONTROL TEST sheet when all of the valves listed have been tested. 


\begin{tabular}{|c|c|c|c|c|c|c|c|}
\hline $\mathrm{N} \exists \triangle \mathrm{L}$ LSF-AC & & & & & & & \\
\hline$\exists S 07519 \mathrm{~b}-\mathrm{N}$ & & & & & & & \\
\hline$N \exists d O$ DEP $-\mathrm{A}$ & & & & & & & \\
\hline 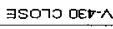 & & & & & & & \\
\hline NJdO $L E L-A$ & & & & & & & \\
\hline$\exists S 07 \supset 1 \varepsilon L^{-\lambda}$ & & & & & & & \\
\hline O SOd EgZ-AC & & & & & & & \\
\hline a sod Egz- $\wedge$ & & & & & & & \\
\hline$\forall S O d E g z-\wedge$ & & & & & & & \\
\hline 0 sod $192-\lambda$ & & & & & & & \\
\hline a sod $192-\lambda$ & & & & & & & \\
\hline$\forall \operatorname{sod} 192 \wedge$ & & & & & & & \\
\hline $0 \mathrm{sod} \nabla 92-\lambda$ & & & & & & & \\
\hline g SOd VSz-AC & & & & & & & \\
\hline$\forall$ SOd DSE-AC & & & & & & & \\
\hline O sod $\varepsilon s z-\lambda 0$ & & & & & & & \\
\hline 日 SOd ESZ $A$ & & & & & & & \\
\hline$\forall \mathrm{sOn} \varepsilon \mathrm{sz}-\lambda$ & & & & & & & \\
\hline $\mathrm{N} \exists d O \quad Z s z-\wedge \mathrm{O}$ & & & & & & & \\
\hline ヨSOาว ZפZ-A & & & & & & & \\
\hline$O S O d L E-A C$ & & & & & & & \\
\hline asod $152-\lambda$ & & & & & & & \\
\hline$\forall S O A$ ISZ-AC & & & & & & & \\
\hline a SOd OSZ $\lambda \mathrm{C}$ & & & & & & & \\
\hline a SOd $052-A$ & & & & & & & \\
\hline$\forall \mathrm{sOd}$ OSz-AC & & & & & & & \\
\hline دSOd 6Rz-AC & & & & & & & \\
\hline a SOd $602 \wedge$ & & & & & & & \\
\hline$\forall$ SOd $60 Z-A C$ & & & & & & & \\
\hline$O S O d \theta P Z-A$ & & & & & & & \\
\hline gSOd $8 \mathrm{PZ} Z-\wedge$ & & & & & & & \\
\hline$\forall$ SOd $B \forall Z-\lambda c$ & & & & & & & \\
\hline $0 S O d \angle q Z-\lambda C$ & & & & & & & \\
\hline BSOd $\angle P Z-A C$ & & & & & & & \\
\hline$\forall S O d \angle V Z-\lambda$ & & & & & & & \\
\hline SSOd $9 b 2-\lambda c$ & & & & & & & \\
\hline a $S O d g p z-\lambda C$ & & & & & & & \\
\hline$\forall$ SOd $99 \mathrm{Z}-\mathrm{An}$ & & & & & & & \\
\hline 0 SOd $5 \mathrm{bZ}-\wedge \mathrm{C}$ & & & & & & & \\
\hline$\theta S O d \mathrm{gPZ} Z \wedge \mathrm{C}$ & & & & & & & \\
\hline$\forall \operatorname{sod} \operatorname{st} Z \cdots A$ & & & & & & & \\
\hline$O S O d P R Z-\wedge d$ & & & & & & & \\
\hline Q S SOd $p 0 Z-\wedge$ & & & & & & & \\
\hline$\forall S O d \nabla \nabla C-A C$ & & & & & & & \\
\hline OSDA EDZ $-A C$ & & & & & & & $\underline{\underline{p}}$ \\
\hline asod EpZ $2 \wedge$ & & & & & & & 禞 \\
\hline$\forall S O d E D Z-\wedge$ & & & & & & & 蛋 \\
\hline $0 \leq 0 d Z P Z-\wedge$ & & & & & & & \\
\hline 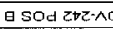 & & & & & & & 罣 \\
\hline$\forall S O d z+Z-\lambda C$ & & & & & & & \\
\hline $3 \operatorname{sod} 2 \varepsilon l-\lambda$ & & & & & & & \\
\hline ㅂsod $z \varepsilon l-\lambda$ & & & & & & & \\
\hline$\forall$ sod $2 \varepsilon 1-\lambda$ & & & & & & & \\
\hline 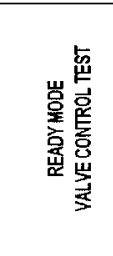 & 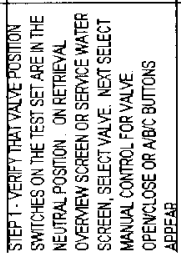 & 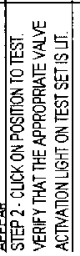 & 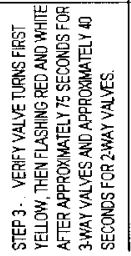 & 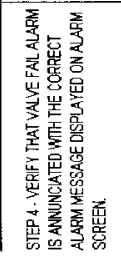 & 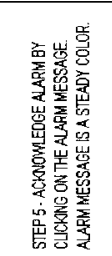 & 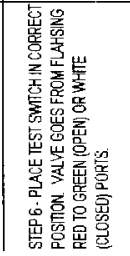 & 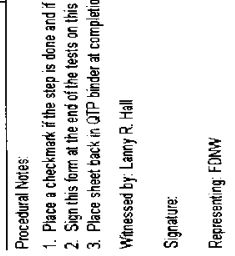 \\
\hline
\end{tabular}


HNF-3334, Rev 0

\subsection{FLOW CONTROL VALVES}

LH 9.2.1 Set test set FCV-131 position dial to a value greater than $10 \%$, and verify valve FCV-131 on the screen is green.

LH 9.2.1.1 Adjust the potentiometer on the test set from 0 to $100 \%$. Verify the valve symbol is white below $5 \%$ open. and remains green between $5 \%$ and $100 \%$ open.

LH 9.2.1.2 On the Test set place the FCV-131 switch in the OPEN position. Verify the valve symbol remains green.

$\mathrm{LH}$ 9.2.1.3 Place the FCV-131 potentiometer on the test set to $0 \%$ and switch in the CLOSE position. Verify that the valve symbol turns white.

\subsection{VERIFY AUTO CHECK FOR EACH MODE}

LH 9.3.1 Place all valves in the AUT0 mode. Refer to the following Table:

LH_ 9.3.2 when in the READY Mode, assure CSS READY is on, select a valve identified in the left column, and place it in the MANUAL Mode. Bring up the MODE SELECT page. From the table. Select the related Mode from the right hand column and select it on the MODE SELECT menu. Verify that the following error message appears:

"Please put the following valves in AUTO and re-select the MODE."

(With the appropriate valve listed.)

LH_ 9.3.3 Return to the overview screen. place the appropriate valve in AUTO. return to the MODE SELECT page, and re-select the MODE. Verify no error messages. Place a check mark in the table and initial the entry.

LH_ 9.3.4 Click the MODE button to de-select the mode. Verify the blue outiine disappears.

Repeat steps 9.3.2 through 9.3.4 for the remainder of the table. 
HNF-3334, Rev 0

\begin{tabular}{|c|c|c|c|}
\hline VALVE NUMBER & MODE & $\begin{array}{l}\text { ERROR MESSAGE } \\
\& \text { RECOVERY? }\end{array}$ & $\begin{array}{l}\text { COMPLETED OK } \\
\text { INITIALS }\end{array}$ \\
\hline MOV-250 & (IN2) 241-A-B To AP-102 & & $\mathrm{LH}$ \\
\hline MOV-244 & (RTN2) AP-102 To 241-A-B & & $\mathrm{LH}$ \\
\hline MOV -243 & (RTF2) AP-102 To 241-A-B Flush & & $\mathrm{LH}$ \\
\hline MOV -261 & (DIL2) Add Diluent to AP-102 & & $\mathrm{LH}$ \\
\hline MOV -253 & (ITR2) AP-102 In Tank Recirculation & & $\mathrm{LH}$ \\
\hline MOV -132 & (ITF2) AP-102 In Tank Flush & & $\mathrm{LH}$ \\
\hline MOV-242 & (WT2) AP-102 To AP Valve Pit & & $\mathrm{LH}$ \\
\hline FCV-131 & (PTF2) Flush AP-102 valve Pit & & LH \\
\hline MOV -245 & (ILD2) AP-102 In Line Dilution & & $\mathrm{LH}$ \\
\hline MOV -247 & (IN4) 241-A-B To AP-104 & & LH \\
\hline MOV -248 & (RTN4) AP-104 To 241-A-B & & LH \\
\hline MOV-251 & (RTF4) AP-104 To 241-A-B Flush & & $\mathrm{LH}$ \\
\hline MOV -263 & (DIL4) Add Diluent to AP-104 & & LH \\
\hline MOV -254 & (ITR4) AP-104 In Tank Recirculation & & $\mathrm{LH}$ \\
\hline MOV -249 & (ITF4) AP-104 In Tank Flush & & $\mathrm{LH}$ \\
\hline MOV -246 & (WT4) AP-104 To AP Valve Pit & & LH \\
\hline FCV -131 & (PTF4) Flush AP-104 Valve Pit & & $\mathrm{LH}$ \\
\hline MOV-249 & (ILD4) AP-104 In Line Dilution & & $\mathrm{LH}$ \\
\hline MOV -252 & (HVT) 241-A-B to VIT Facility & & $\mathrm{LH}$ \\
\hline
\end{tabular}

10 MODE SWITCHING INTERLOCKS \& MODE VALVE ALIGNMENT

\subsection{INTERLOCK MATRIX}

Using the MODE INTERLOCK MATRIX on the following page, verify for every combination of MODE, beginning in the upper left hand corner, that blank mode 
intersections cannot be selected from the MODE SELECT screen. Verify that intersections with an " 0 ", can be selected individually from the mode select screen.

\subsection{DOCUMENTATION}

LH Mark each box in the matrix with a check as the test is successfully completed. 


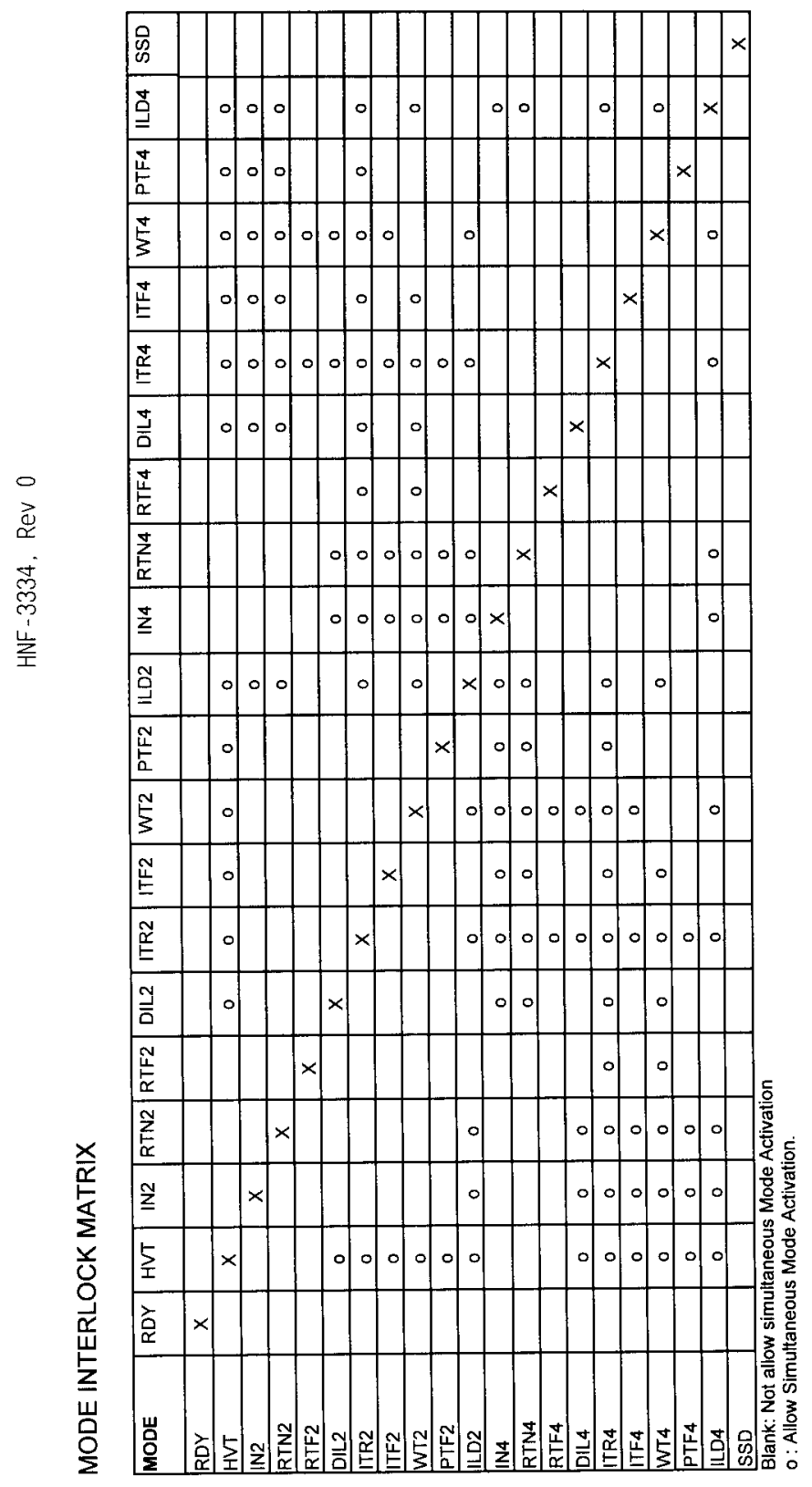




\subsection{VALVE ALIGNMENT}

Using the MATRIX on the following page, start in the Ready Mode (RDY), and advance downward through the MODES. At any MATRIX intersection with a "m". verify that the valve is commanded to go to that position by observing the lights on the test set. A "m" indicates the desired valve position. Only those valve positions with a " " need be verified.

10.3 .1

Using the MATRIX, verify that the appropriate valve energization lights are lit. Then "move" valve (with test position switches) into the correct position as each valve is verified. Use a yellow marker to mark each cell with a " " as the valve is verified.

10.3 .2

As each mode step is completed, verify that the appropriate step is checked off on the Mode Status window and proper valve energization lights are lit for the next step.

10.3 .3

Verify the current mode button is out 7 ined in blue. When finished with a MODE, click MODE button again to stop/exit MODE.

10.3.4 Repeat steps 10.1.1 - 10.1.3 for each of the remaining modes.

$\mathrm{LH} \quad 10.3 .5$

Verify all cells with a " have been marked as completed in the W-211 VALVE ALIGNMENT MATRIX. 

* تา

m doss $010 V^{-} 200^{-} d^{-} \mathrm{M}$ s) Jרena" OLIV $200^{\circ} \mathrm{d}^{\circ} \mathrm{LM}$

क) OSOd OLARZEL"AON" EMAHD

o) asOd OIN

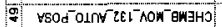

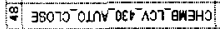

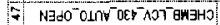

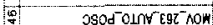

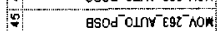

- bod OLntegr how

7 SSOd OANE IgL AOH

4 GsOd OUNY $19 C^{-}$NON

- $\operatorname{cod}$ OunVIgt AOW

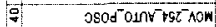

c) acod OLnN" DSt

क) WOd OUAV bST AON

m JSOd OLV EGt AOW

(a) asOd OLIVEST AOW

mi vod Ont Est

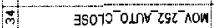

m $\quad \mathrm{AdO} \mathrm{O}^{-} \mathrm{OLN} \mathrm{ZGL}^{-}$hON

mi $08 \mathrm{Cd}^{-} \mathrm{OLNY}-19 \mathrm{C}^{-} \mathrm{nO}$

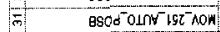

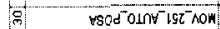

F) Jod OLnY $05 T^{-10 N}$

asod OLIVTOST $\mathrm{NOW}$

N tsod OLIN $05 z^{-}$AOW

a osod Ond $66 t^{\circ} \mathrm{hOW}$

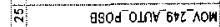

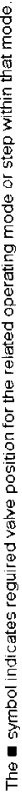

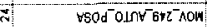

ली $050 d^{-01 n r^{-} 8 t t^{-A} \text { AON }}$

Bsod Ont ant

i vod olnv" abl nom

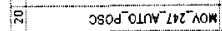

- gsod olnt $2 t z^{2}$ now

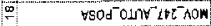

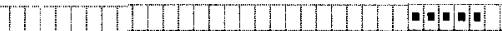

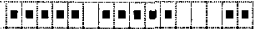

$+4-1$

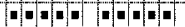

1101

$110+-1$

$=0$

10.10

$100+1$

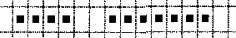

$-4-1-$

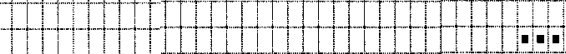

1

10

$-10$

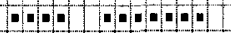

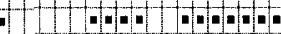

000

$1+\infty$

-ualo

$-1+1=$

- H.

1 - 100

-

-

$-\infty$

- ala

-10 -1

II घ)

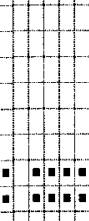

asodolnt"grt AON

6. GsOd OLnt $9 \tau^{-} \mathrm{AOH}$

6 bSOd Olne $94 \tau^{-} \mathrm{AON}$

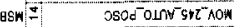

- esodount stron

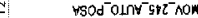

- asod OUN" bit now

- gsodontritiom

- WOdOLOTDETAN

o osodontertion

a) asOdolnterthom

- wsorolayetriak

o osodolonitrítom

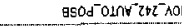

rsod"OLIVI

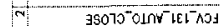

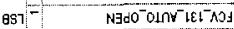

$1-1-1$

a

$+1+1$

$-1+\infty=-$

C+C + -

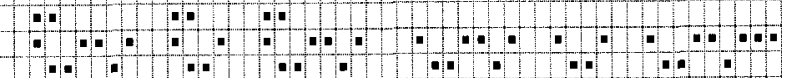
g g o

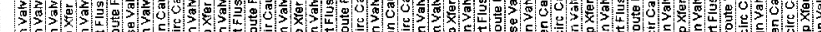

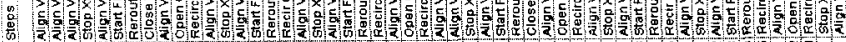
go 


\section{INTERLOCK BYPASSES}

This section was removed due to no VFD devices available for testing. This section will be tested during the acceptance test procedure (ATP).

12 ENCLOSURE WT-ENCL-100 ANALOG DEVICES

Switch to "Process Overview", "Tank 241-AP-102 Overview", or "Tank 241-AP-104 Overview" screens for this portion of the test.

Acknowledge each alarm after it is verified.

\subsection{PRESSURE AND LEVEL INDICATORS}

NOTE: The input current is given as a percentage of 4-20mA current signal $(0 \%=4 \mathrm{~mA}$ and $100 \%=20 \mathrm{~mA})$.

LH 12.1.1 To simulate WST-PT-102 (Tank 102 Dome Pressure). disconnect 2.4K resistor from TB-3 terminal 1.

$\underset{\mathrm{LH}}{\mathrm{L}} 12.1 .2$

Connect 4-20mA transmitter simulator (in $\mathrm{mA}$ out mode) set at $0 \%$ to terminals TB-3 terminals $1(+)$ and $2(-)$. Then perform the following:

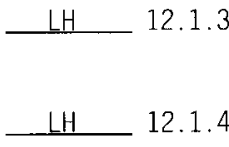

Verify pressure indicated on screen for WST-PI-102 indicates -10 inches W.G.

Vary the input current from 0 to $100 \%$ and verify the range of the pressure indicator on screen varies from -10" to 5" W.G., and alarms occur as listed in D00. App. B.

LH 12.1.5 Remove simulator.

L 12.1.6 Reconnect 2.4K resistor.

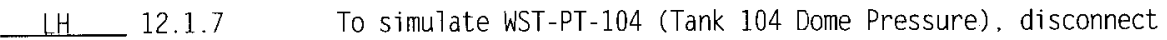
2.4K resistor from terminal TB-3 terminal 4.

LH 12.1.8 Connect a 4-20mA transmitter simulator (in mA out mode) set at $0 \%$ to terminals $4(+)$ and $5(-)$. Then perform the following:

LH_ 12.1.9 Verify pressure indicated on screen for WST-PI-104 indicates -10 inches $W . G$. 
HNF-3334, Rev 0

LH 12.1 .10

Vary the input current from 0 to $100 \%$ and verify the range of the pressure indicator on screen varies from -10 " to $5 "$ W.G. , and alarms occur as listed in D0O. App. B.

LH 12.1.11 Remove simulator.

LH_ 12.1.12 Reconnect 2.4K resistor.

LH 12.1.13 To simulate WST-LIT-106 (Tank 106 Waste Leve1), disconnect 2.4K resistor from $\mathrm{TB}-3$ terminal 11 .

LH 12.1.14 Connect 4-20mA transmitter simulator (in mA out mode) set at $0 \%$ to terminals TB-3 terminals $11(+)$ and $10(-)$. Then perform the following:

LH 12.1.15 Verify level indicated on screen for WST-LI-106 indicates 0 inches.

LH 12.1 .16

Vary the input current from 0 to $100 \%$ and verify the range of the leve 7 indicator on screen varies from 0 to 450 inches.

LH 12.1.17 Remove simulator.

LH $\quad 12.1 .18 \quad$ Reconnect 2.4K resistor

LH 12.1 .19 To simulate WST-LIT-108 (Tank 108 Waste Leve1), disconnect 2.4K resistor from $T B-3$, termina 1.7 .

LH 12.1.20 Connect 4-20mA transmitter simulator (in mA out mode) set at $0 \%$ to terminals TB-3 terminals $17(+)$ and $16(-)$. Then perform the following:

LH_ 12.1.21 Verify level indicated on screen for WST-LI-108 indicates 0 inches.

LH 12.1.22 Vary the input current from 0 to $100 \%$ and verify the range of the level indicator on screen varies from 0 to 450 inches.

LH_ 12.1.23 Remove simulator.

LH $\quad 12.1 .24 \quad$ Reconnect 2.4K resistor. 
To simulate WST-LIT-222 (Tank 102 Waste Leve1), disconnect 2. $4 \mathrm{~K}$ resistor from TB-3, terminal 23.

L.H 12.1 .26

Connect 4-20mA transmitter simulator (in $\mathrm{mA}$ out mode) set at $0 \%$ to termina 75 TB-3 terminals $23(+)$ and $22(-)$. Then perform the following:

$\underline{\mathbf{L H}} \mathbf{1 2 . 1 . 2 7}$

Verify level indicated on screen for WST-LI-222 indicates 0 inches.

$\underline{L}+12.1 .28$

Vary the input current from 0 to $100 \%$ and verify the range of the level indicator on screen varies from 0 to 450 inches.

L 12.1.29 Remove simulator.

L L 12.1.30 Reconnect 2.4K resistor.

LH 12.1.31 To simulate WST-LIT-224 (Tank 104 Waste Leve]), disconnect 2.4K resistor from TB-3, terminal 29.

L

Connect 4-20mA transmitter simulator (in $\mathrm{mA}$ out mode) set at $0 \%$ to terminals TB-3 terminals $29(+)$ and $28(-)$. Then perform the following:

LH 12.1 .33

Verify level indicated on screen for WST-LI-224 indicates -0 inches.

12.1 .34

Vary the input current from 0 to $100 \%$ and verify the range of the level indicator on screen varies from 0 to 450 inches.

L

\begin{tabular}{l}
$\mathrm{LH}$ \\
\hline
\end{tabular} 12.1.36 Reconnect 2.4K resistor.

13 TEST COMPLETION

13.0.1 Turn off a11 power.

13.0.2 Remove all simulation devices.

13.0.3 Open atl fuse holders.

13.0.4 Have Electricians remove all power cables \& cables to Test Set. 
HNF-3334, Rev 0

13.0.5 Remove two UPSs and deliver to Project Engineer. (Project Engineer will arrange to have UPSs connected to a suitable power source to maintain UPS internal batteries in a "float charge" condition.)

13.0 .6

Save final RCS "as-built" software on removable electronic media (floppy disk or CD ROM).

13.0.7 Complete review and approvals of this QTP, and deliver final documentation to Test Director.

13.0.8 $\quad$ END 
APPENDIX A - HMI SCREENS

FIGURE 1 - TWRS OVERVIEW SCREEN

FIGURE 2 - ITRS OVERVIEW SCREEN

FIGURE 3 - INITIAL TANK RETRIEVAL SYSTEMS RCS FOR DST 241-AP-102 \& 241-AP-104

FIGURE 4 - RETRIEVAL SYSTEM OVERVIEW

FIGURE 5 - SCREEN LIST

FIGURE 6 - TYPICAL RETRIEVAL SETUP

FIGURE 7 - MODE LIST

FIGURE 8 - BYPASSABLE PLC INTERLOCKS

FIGURE 9 - TANK 241-AP-102 OVERVIEW

FIGURE 10 - TANK 241-AP-104 OVERVIEW

FIGURE 11 - TANK 241-AP-102 MIXER PUMP SPEED VS. POSITION PROFILE

FIGURE 12 - TANK 241-AP-104 MIXER PUMP SPEED VS. POSITION PROFILE

FIGURE 13 - TANK 241-AP-102 TEMPERATURE PROFILE

FIGURE 14 - TANK 241-AP-104 TEMPERATURE PROFILE

FIGURE 15 - DILUENT/FLUSH SYSTEM

FIGURE 16 - SERVICE WATER SYSTEM

FIGURE 17 - ALARM SETPOINT

FIGURE 18 - TREND SELECTION

FIGURE 19 - CONTROL SYSTEM HARDWARE SETUP

FIGURE 20 - ACTIVE PLC INTERLOCKS TABLE 


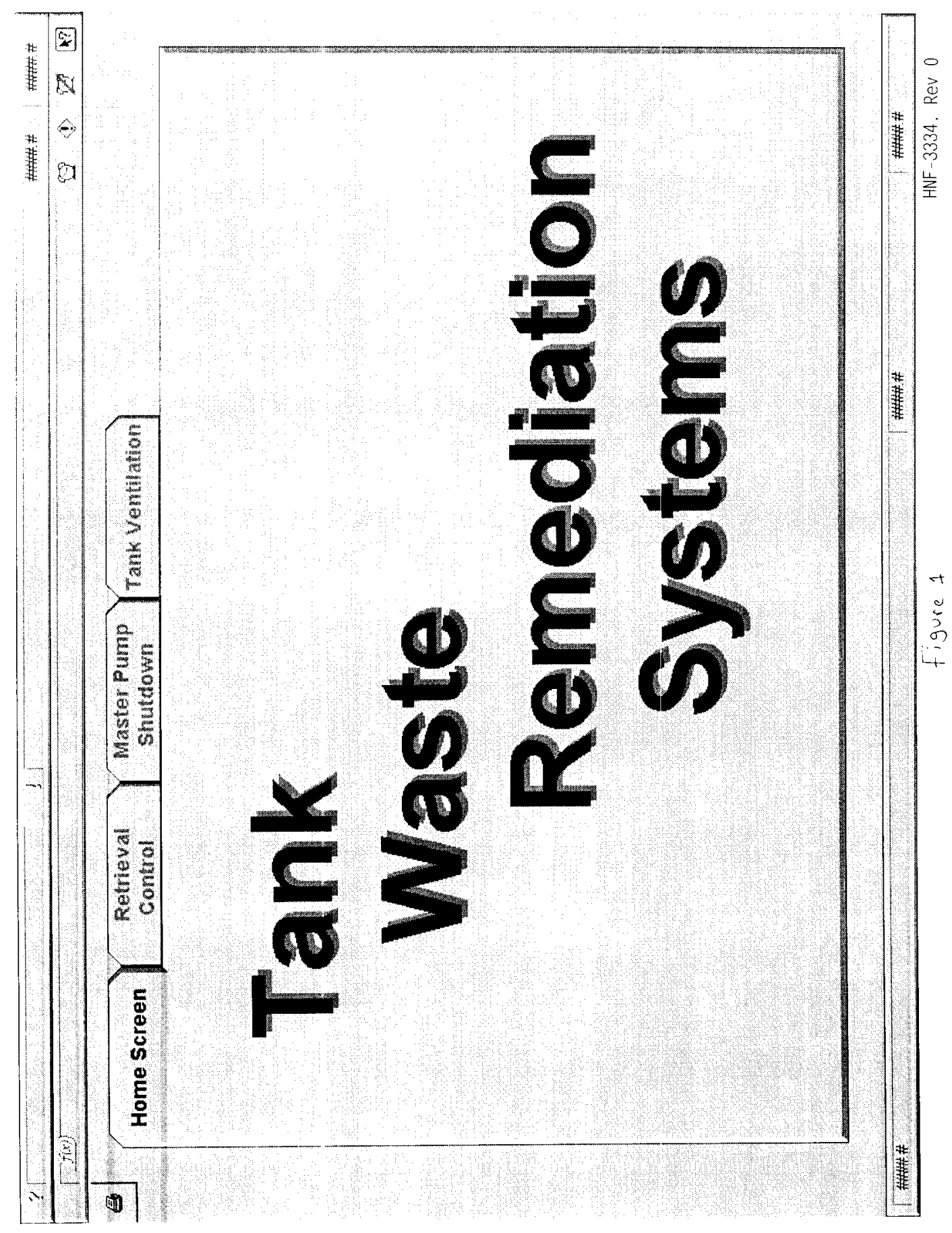




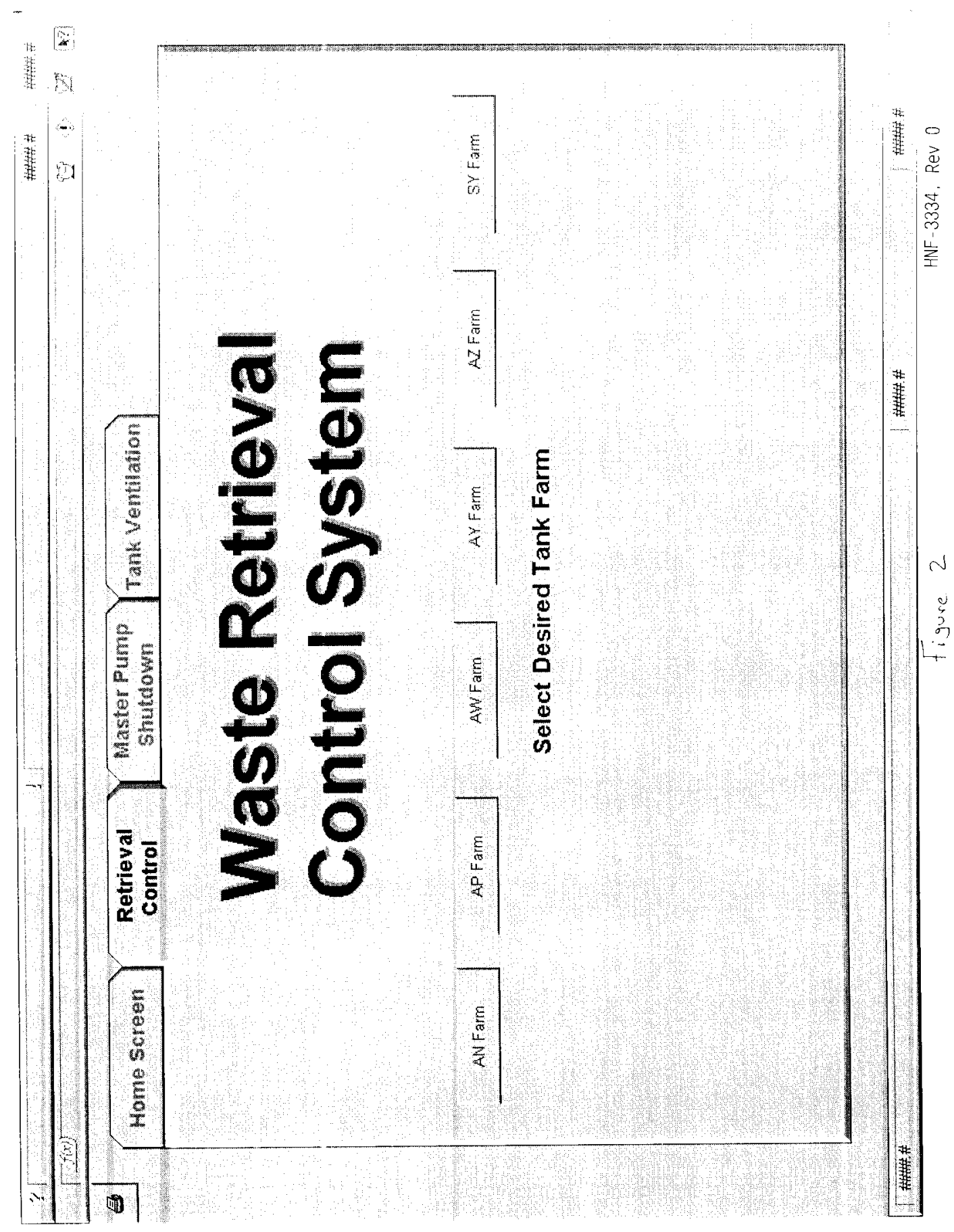


㐟踓
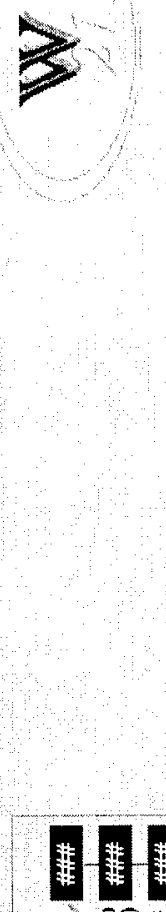

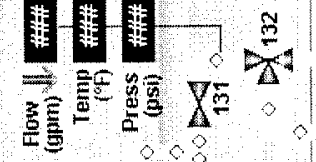

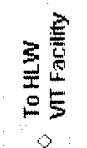

誨

禹垴。

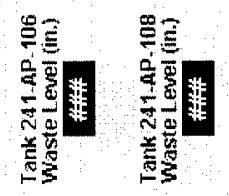

है?

36) 渄 $\frac{a}{a}=$

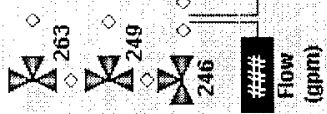

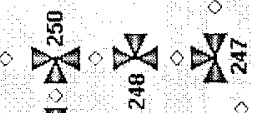

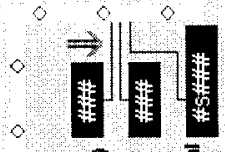

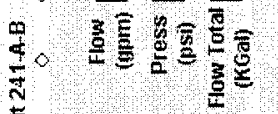

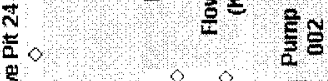

(3)

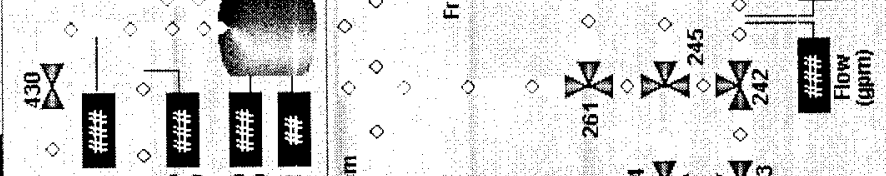
च)
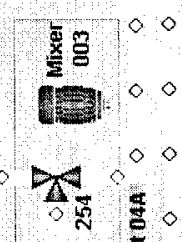

0
$\frac{8}{2}$
$\frac{\mathrm{E}}{2}$
$\mathrm{E}$ $\circ$

$\vec{d}$

峁

崖 


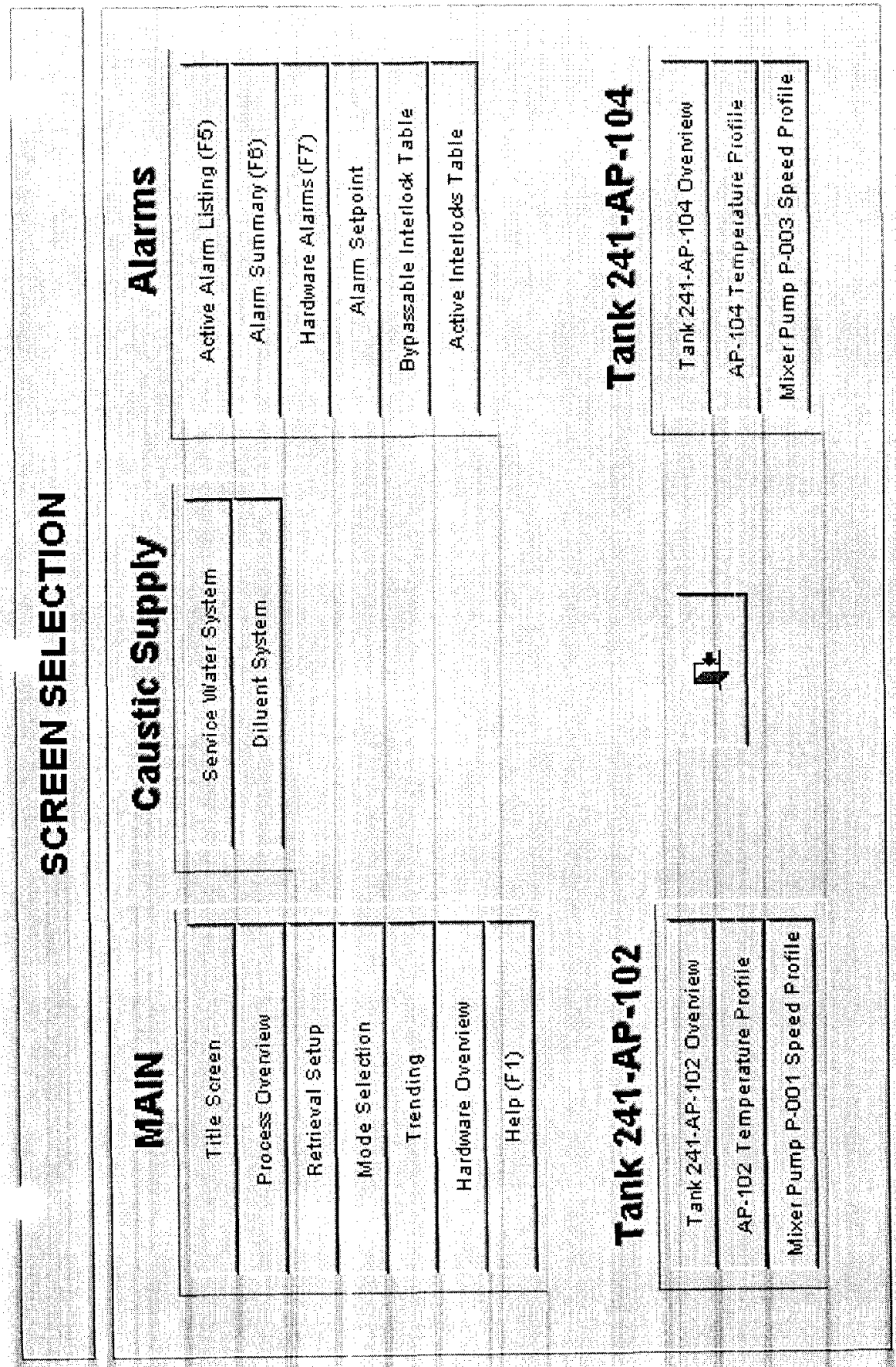

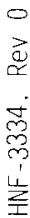

10

乌ु 


\section{RETRIEVAL SETUP}

\begin{tabular}{|l|l|l|l|}
\hline & AP -102 & AP -104 & \\
\hline RTF: Flush to Transfer Pump & 400 & 400 & secs \\
\hline RTF: Flush to Valve Pit AP.A.B & 400 & 400 & secs \\
\hline DIL: Diluent Addition to Tank & 0 & 0 & gals \\
\hline ITF: Flush to Transfer Pump & 400 & 400 & secs \\
\hline ITF: Flush to Tank & 400 & 400 & secs \\
\hline PTF: Flush to Transfer Pump & 400 & 400 & secs \\
\hline PTF: Flush to Receiving Tank & 400 & 400 & secs \\
\hline & & $4 \%$ & \\
\hline & & & \\
\hline
\end{tabular}




\section{MODES LIST}

Tank 241-AP-102

Tank 241 -AP-104

241-A-B TOAP-102

AP. 102 To 241 - A

AP.102 To 241-A-E Flush

Add Dluent To AP-102

AP. 102 In-T ank Fediroulation

AP-102 In T ank Flush

AP. 102 To AP Value Fit

Flush AP 102 Value Pit

AP-102 In-Line Dilution
241-A-B TO AP 104

A.P.104 To 241-A.E

AP-104 To 241-A-B Flush

Add Dluent To AP-104

AP-104 In-T ank Recirculation

AP. 104 In T ank Flush

AP. 104 To AP Valve Pit

Flush AP 104 Value Pit

AP-104 In-Line Dilution

\section{EMERGENCY SHUT DOUNN}

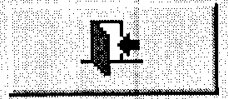

fraure? 


\section{BYPASSABLE PLC INTERLOCKS}

AP-102 AP- 104

(B) Bypas

Bypass

6 Bypass

Bypass

Q eypass

Bypass

Bypass

Bypass

Bupass

0 Bypass

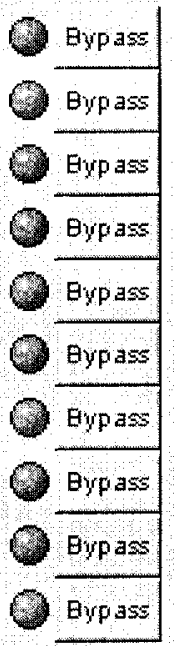

Interlocks

Transfer Pump: Discharge Pressure Hi-Hi

Transfer Pump: Tank Waste Level Lo-Lo

Transfer Pump: Motor current $\mathrm{Hi}-\mathrm{Hi}$

Transfer Pump: Rupture Disk Failure

Transfer Pump: Motor Mlinding Temp Hi-Hi

Transfer Pump: Ready Mode Is ON

Transfer Pump: Float Within $2^{\prime}$ of Waste

Mixer Pump: Tank Waste Level Lo-Lo

Mixer Pump: Motor Current Hi-Hi

Mixer Pump: Suction Float Not Up 

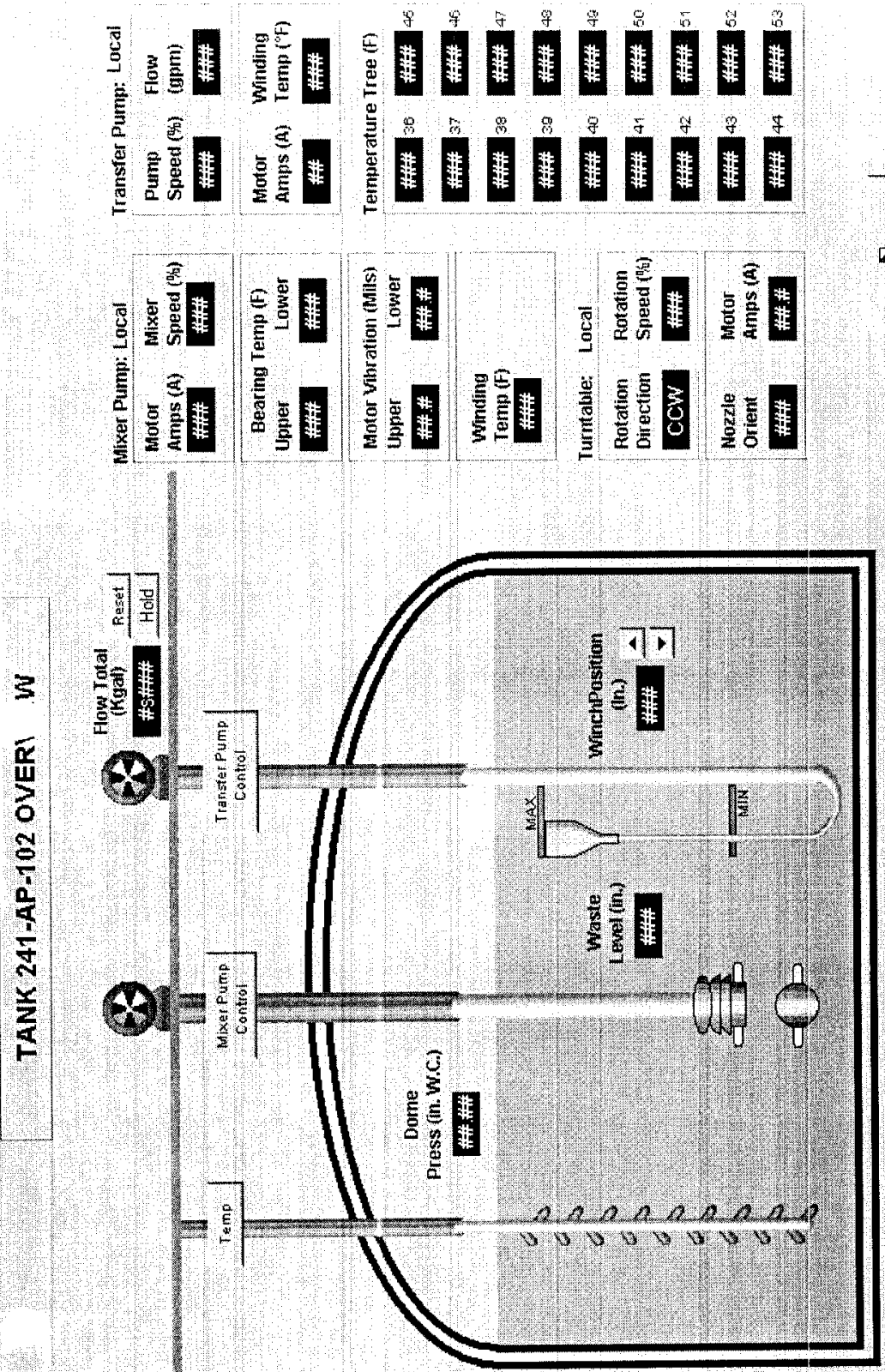


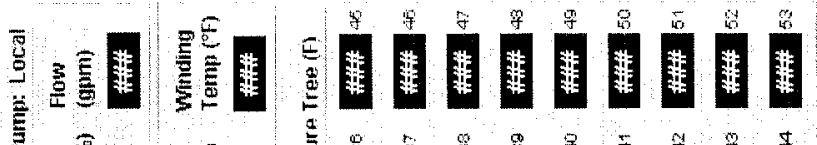

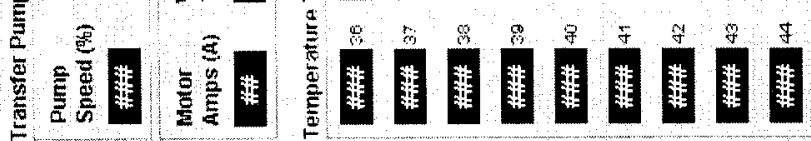

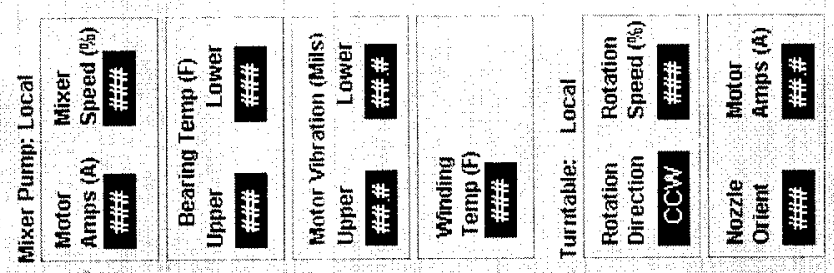




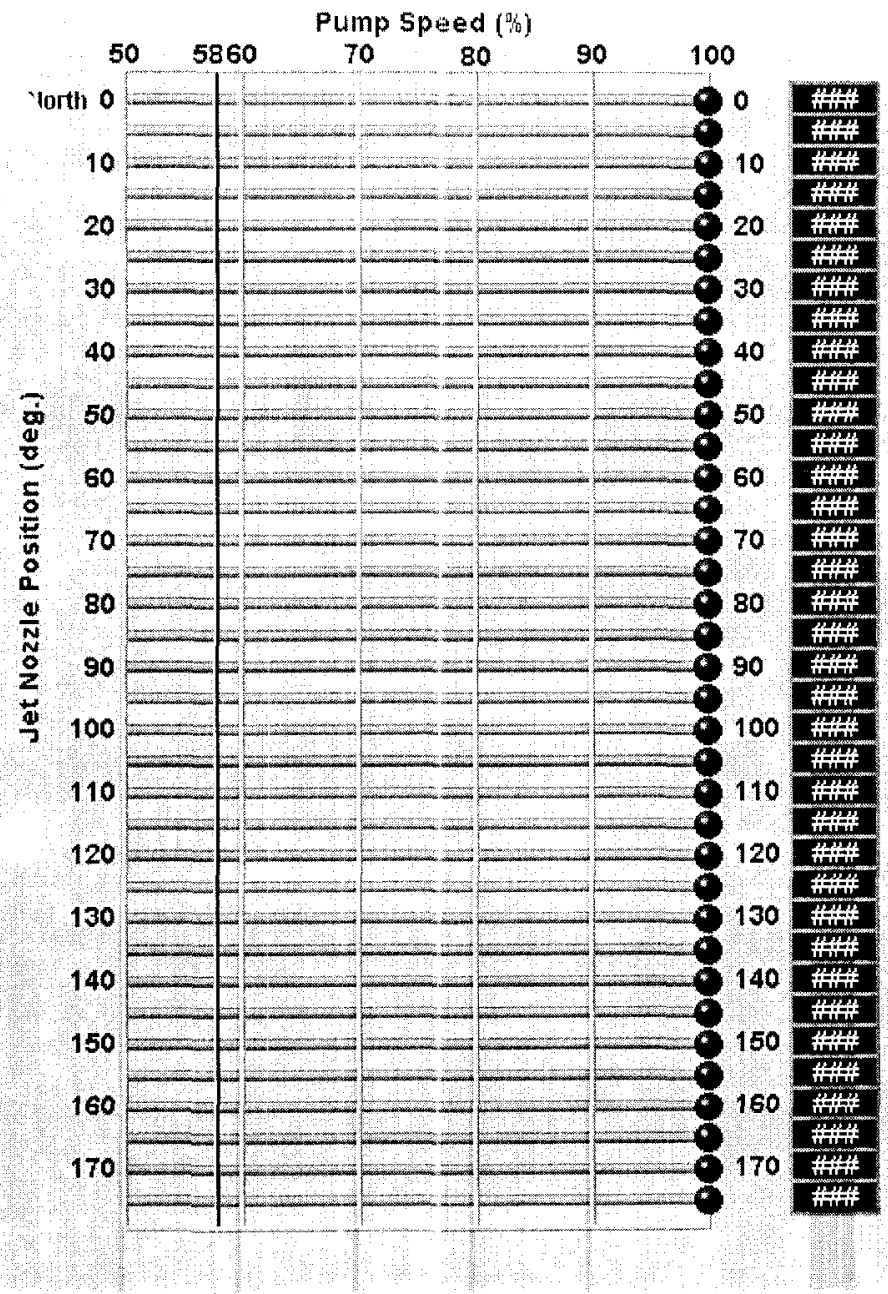

TANK 241-AP-102

MIXER PUMP SPEED vS. POSITION PROFILE

Resel To

vefult spend

\section{7}




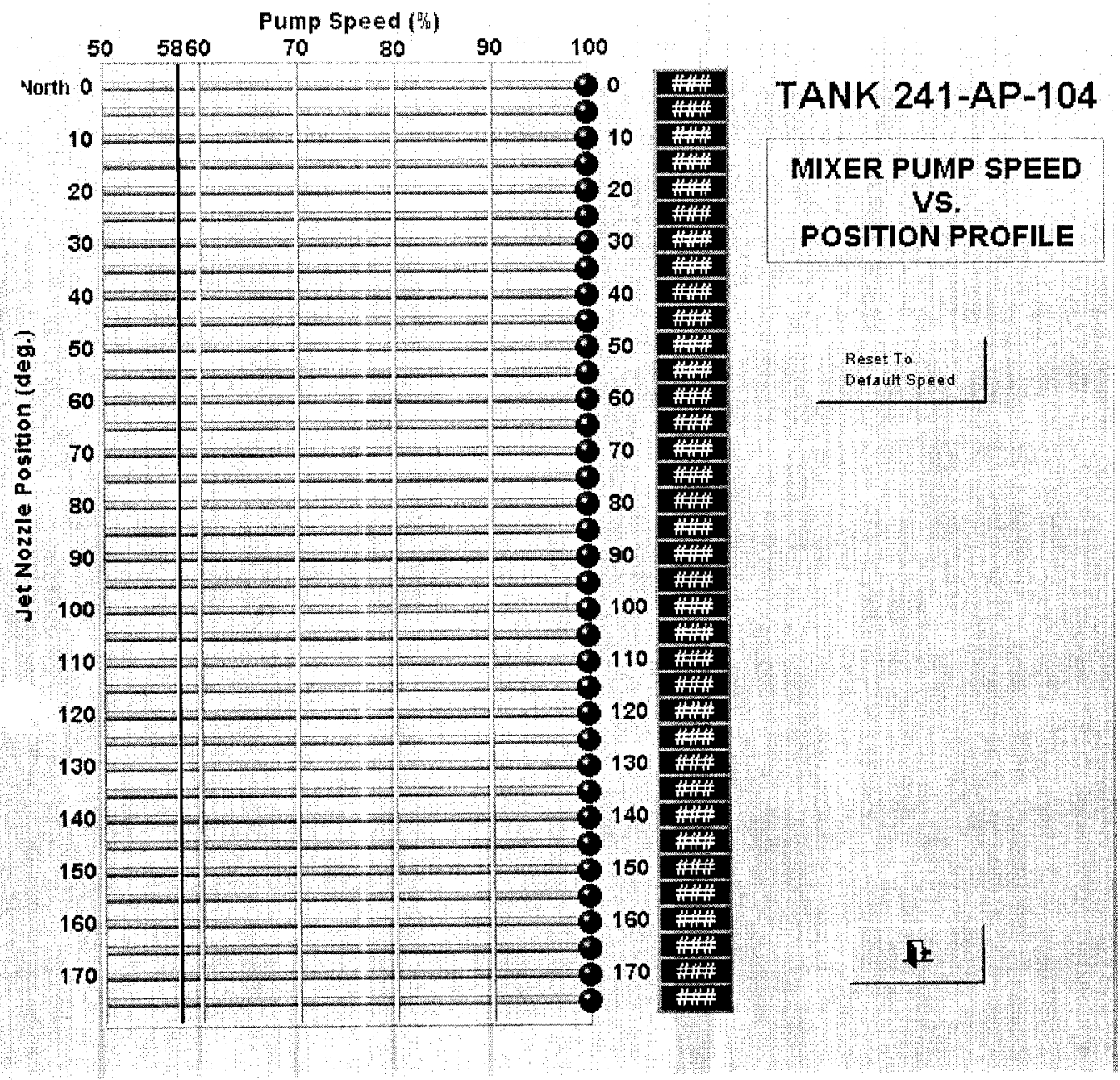




\section{TANK WASTE TEMPERATURES}

\section{TANK 241-AP-102}

TE-36 莘H

TE-37 H萃

TE-38 H莘萃

TE-39 H\#H

TE-40 배퓨

TE-41 HHH

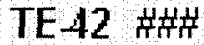

TE 43 \#茾

TE 44 \#茾

TE 45 \#\#

TE 46 H\#H

TE 47 \#\#

TE-48 形获

TE-49 HH

TE 50 \#\#\#

TE-51 H\#

TE 52 茾H

TE-53 \#\#\#
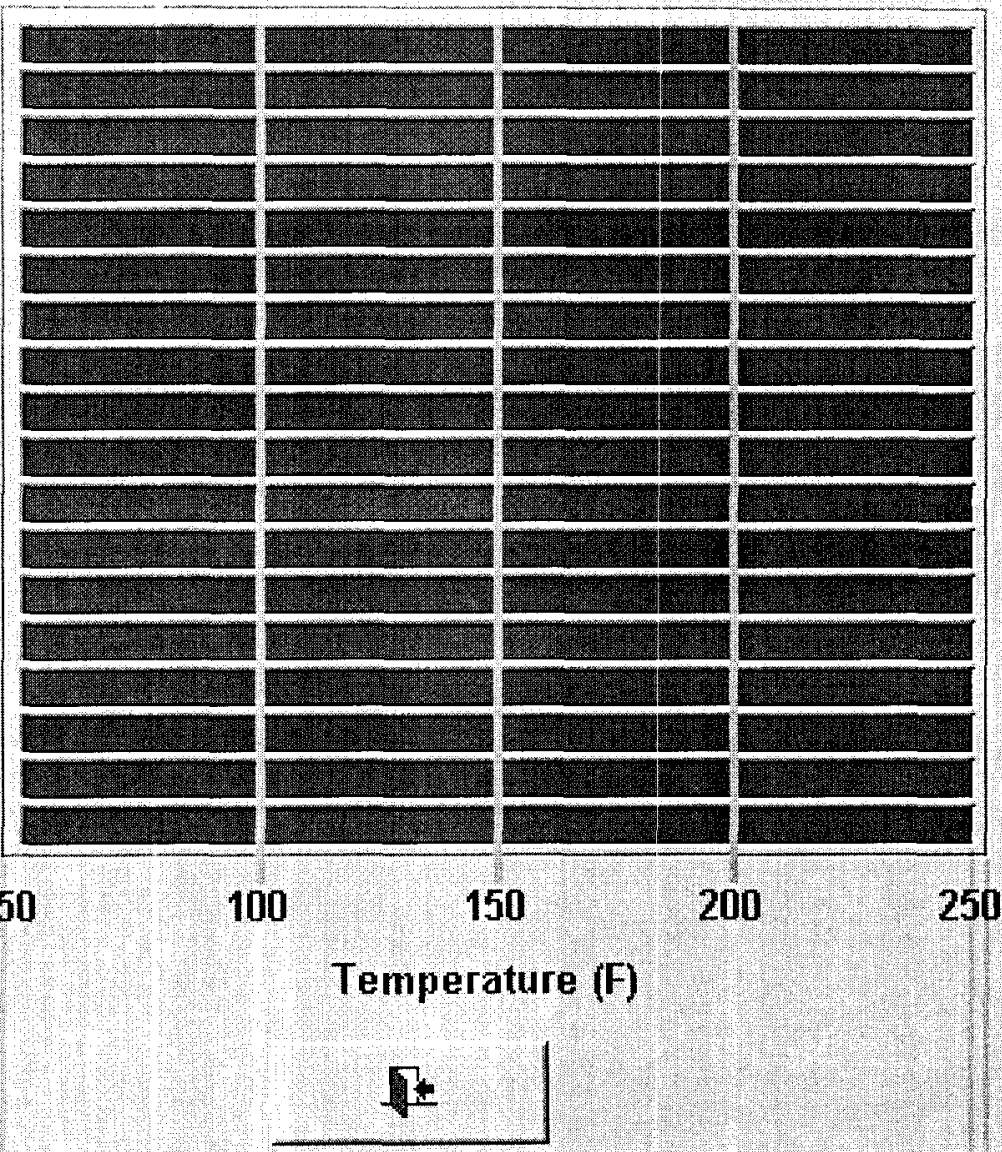


\section{TANK WASTE TEMPERATURES}

\section{TANK 241-AP-104}

TE 36 \#\#

TE-37 퓨퓨

TE-38 배표

TE-39 H茾

TE 40 HH

TE 41 HWH

TE 42 H\#H

TE 43 H H

TE 44 HWH

TE 45 茾椞

TE 46 배패

TE 47 H茾

TE-48 H\#H

TE-49 H\#

TE-50 H茾蓄

TE-51 H莽H

TE-52 배퓨

TE-53 배배

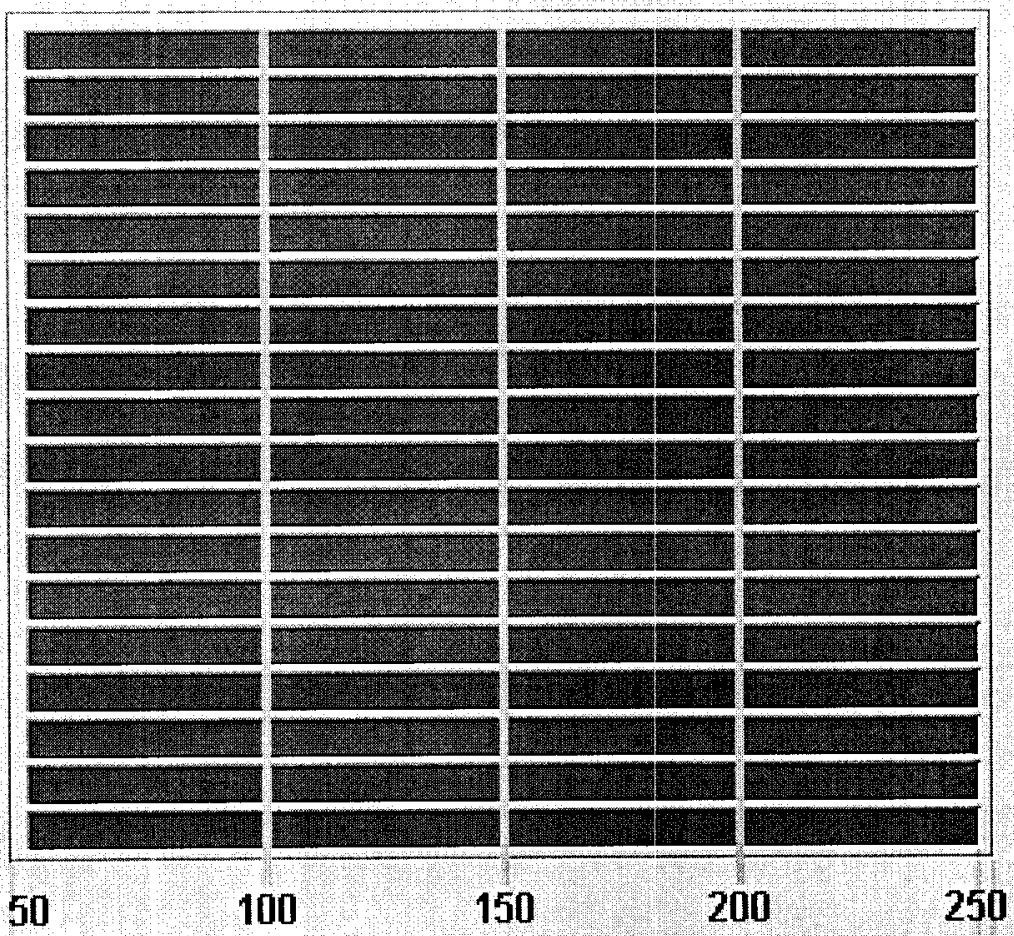

Temperature $(\mathrm{F})$

$$
\text { F* }
$$




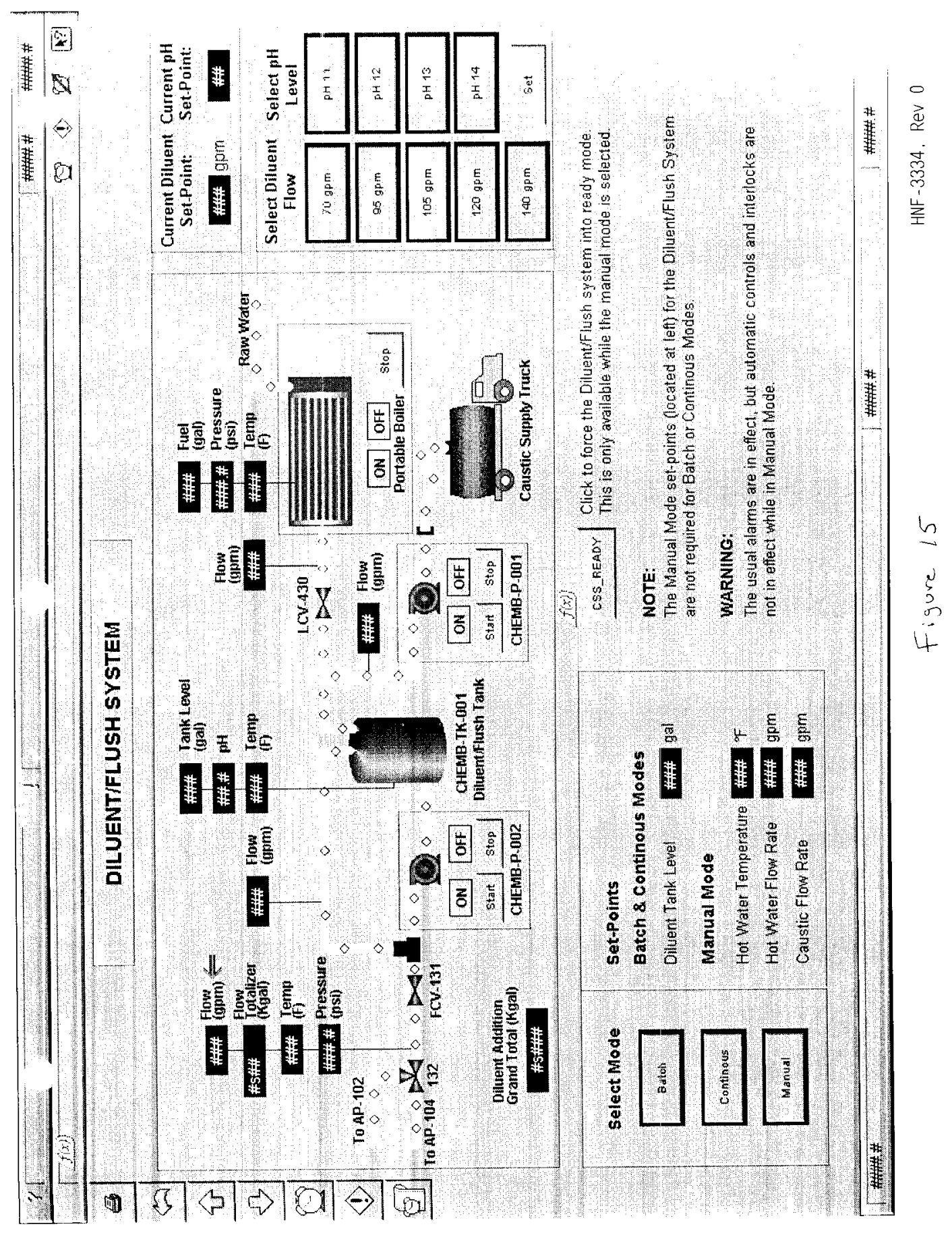




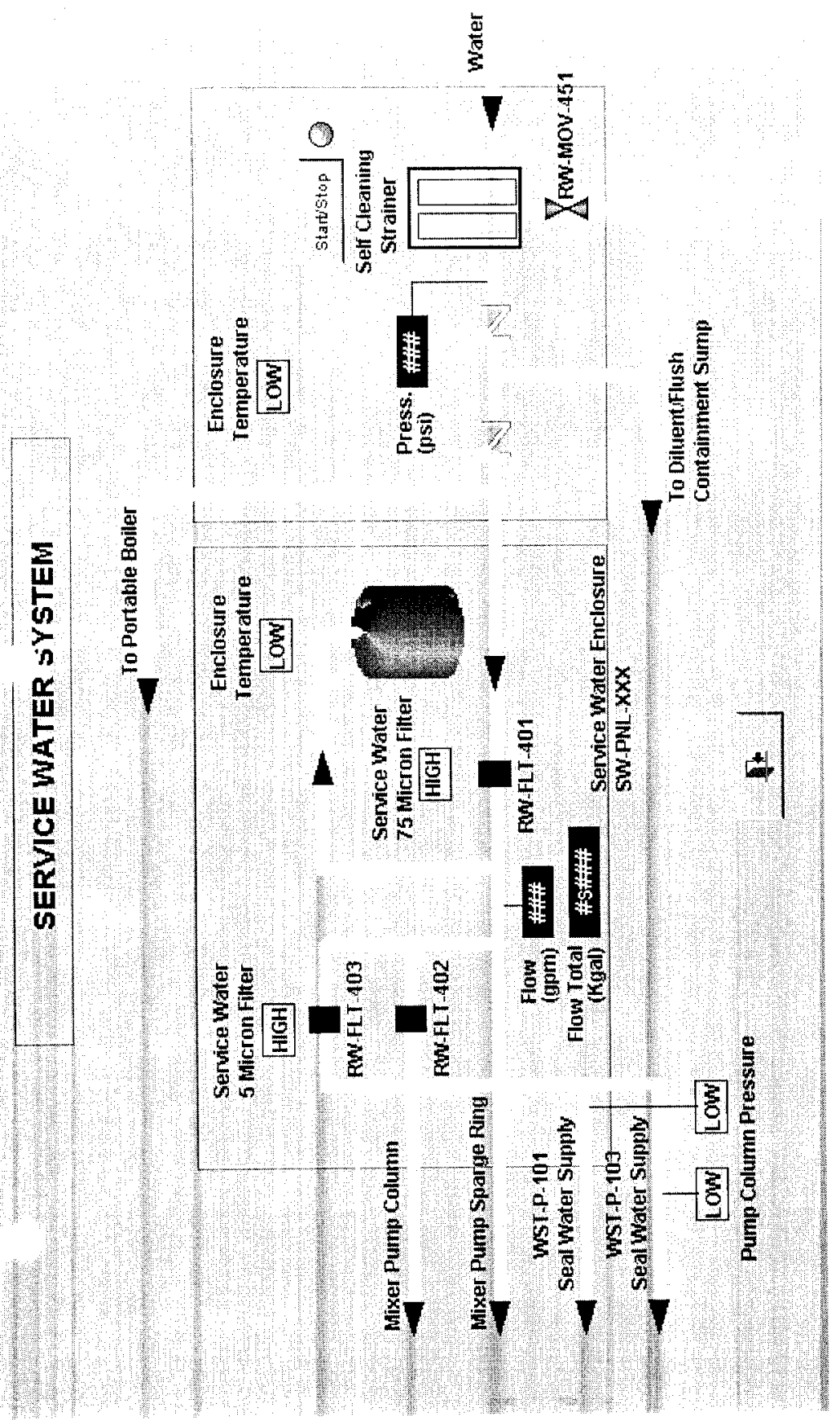




\section{ALARM SETPOINTS}

Tanks

Waste Level (in.)

Temperature Probe Elem. ( $\mathrm{F}$ )

Tank Dome Pressure (in. WO)
Motor Current (Amp)

Motor Upper Vibration (mils)

Motor Lower Vibration (mils)

Motor Upper Bearing Temp (F)

Motor Lower Bearing Temp (F)

Motor Winding Temp. (F)

Turntable Motor Current (Amp)

Tank Waste Level

Transter Pumps

Motor Current (Amp)

Motor Winding Temp. (P)

Flow Output (gpm)

Tank Waste Level

DiluentFlush System

CHEMB-TK-001 Level (in.)

CHEMB-TK-001 Conductivity (us)

CHEMB TKOO1 Temperature (F)

Boiler Fuel Level (in.)
241-AP-102

\begin{tabular}{c|c}
$\mathrm{HiHi}$ & $\mathrm{Hi}$ \\
\hline$\# \#$ & \#\#\# \\
\hline$\# \#$ & $\# \#$ \\
\hline$\#$
\end{tabular}

\section{배패}

H\#\#

\#\#

WIST-P003

Lo LoLO HiHI Hi Lo LOLO

$\mathrm{HiHi} \mathrm{Hi}$

\begin{tabular}{|c|c|}
\hline$\ldots$ & HHW \\
\hline$\#$ & $\mathrm{HH}$ \\
\hline \#\# & H\#\# \\
\hline \#\# & $H \#$ \\
\hline \#\# & \#\#\# \\
\hline 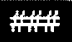 & $\# \#$ \\
\hline$\# \# \#$ & $\# \#$ \\
\hline
\end{tabular}

\#\#

\#\#\#

페

\#\# \#\#

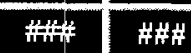

\#\# \#\#\#

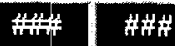

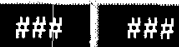

\#\#

\#

\#\#

\#\#

WTP 002

$\mathrm{HiHi} \mathrm{Hi}$

Lo

\#\#\#

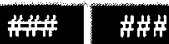

WT-P-019

Hîli Hi

Lo

\#粆

\#\#\#

\#

\#\#\#

\section{\#}

페표

\#車

$\mathrm{HiHi}$

$\mathrm{Hi}$

LO LOLO

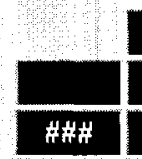

\#\#\#

페에

\#\#

\begin{tabular}{|c|c|}
\hline H\#\# & \#\#\# \\
\hline H\#\# & $\mathrm{H} H \#$ \\
\hline \#茾H & \#\#\# \\
\hline \#希\# & H谋H \\
\hline
\end{tabular}




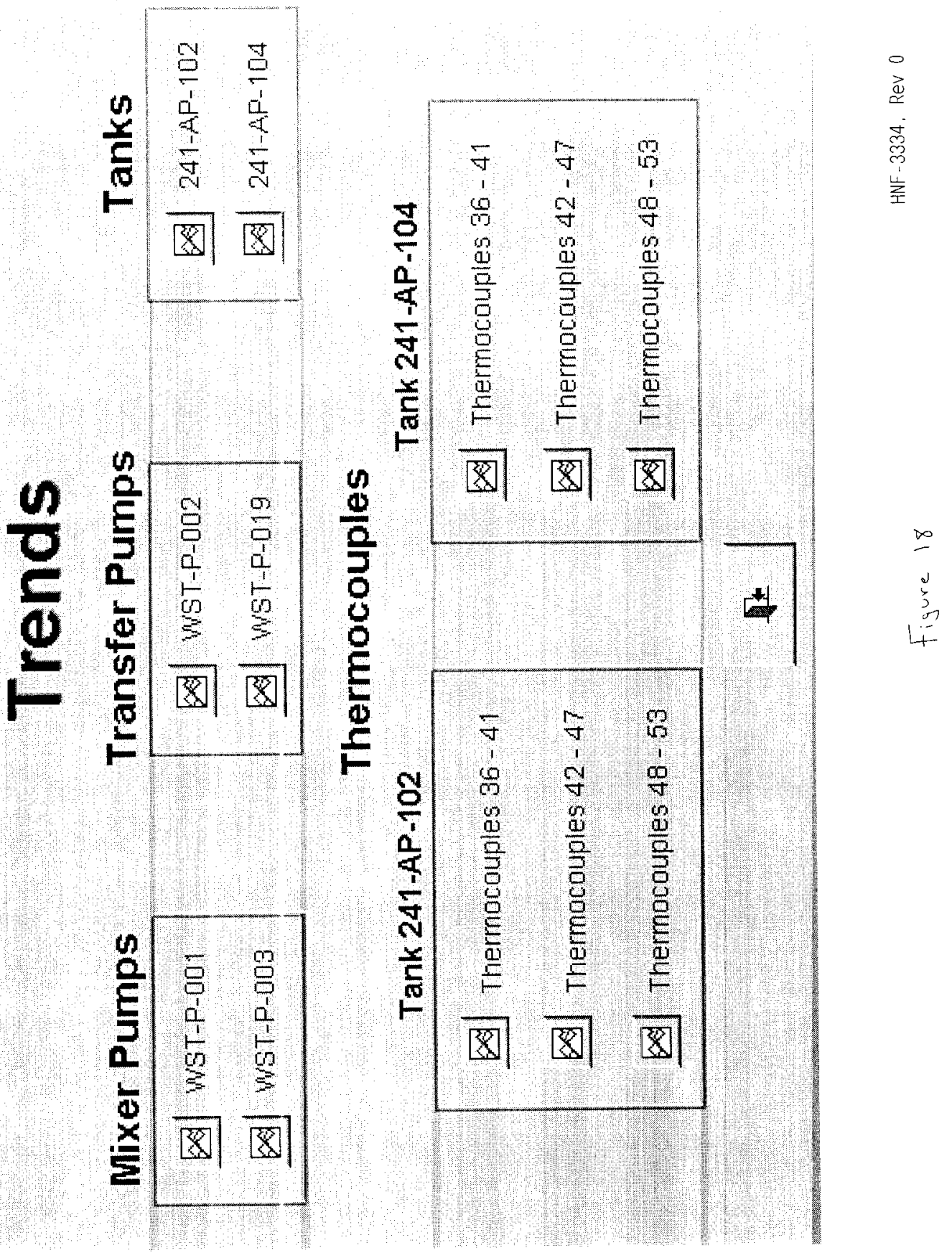




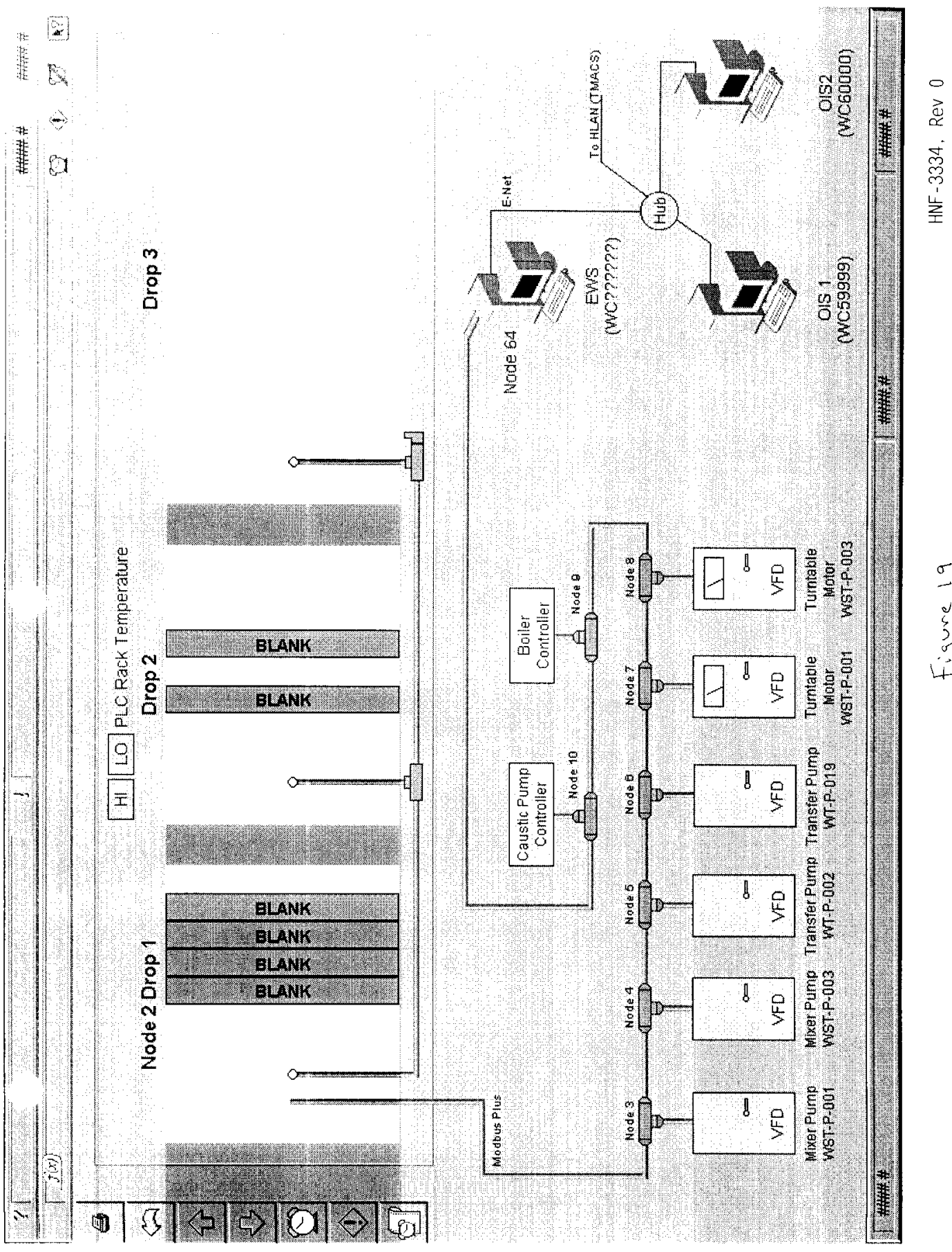


